\title{
RELATOS DE PESQUISAS
CONFLITO TRABALHO-FAMÍLIA:
PESQUISAS CIENTÍFICAS NACIONAIS E
INTERNACIONAIS SOBRE DOCENTES NO ENSINO
SUPERIOR
}

\begin{abstract}
Sérgio Luiz Pedrosa Silva
Doutor em Geografia pela Universidade Federal de Pernambuco, Brasil. Professor da Universidade do Estado do Rio Grande do Norte, Brasil.

E-mail: sergiopedrosa@uern.br
\end{abstract}

Italo Carlos Soares do Nascimento

Mestre em Administração e Controladoria pela Universidade Federal do Ceará, Brasil. Professor da Faculdade Católica do Rio Grande do Norte, Brasil. E-mail: italocarlos25@gmail.com

Géison Calyo Varela de Melo

Mestre em Administração e Controladoria pela Universidade Federal do Ceará, Brasil, Professor da Universidade do Estado do Rio Grande do Norte, Brasil.

E-mail: geisoncalyo@uern.br

\begin{abstract}
Resumo
Este trabalho tem como objetivo analisar como se caracterizam as pesquisas que tratam do conflito trabalho-família relacionadas aos docentes de nível superior em periódicos nacionais e internacionais. A pesquisa classificou-se como descritiva e qualitativa, tendo como procedimento técnico a revisão sistemática, com uma amostra final de 20 artigos sobre o Work-Family Conflict (WFC). A análise se dá através da categorização de Theóphilo e ludícibus (2005) por meio de quatro polos: no epistemológico, os resultados demonstram que quanto aos objetivos, destacam-se os compreensivos e avaliativos; no polo teórico, foram verificadas as abordagens teóricas de Greenhaus e Betel (1985) com mais da metade das abordagens teóricas utilizadas, destacando-se as temáticas maternidade e percepção de gênero, evidenciando um ambiente laboral desfavorável para o feminino; no polo metodológico, predominaram as pesquisas fenomenológicas hermenêuticas e positivistas; no polo técnico, prevaleceram as pesquisas qualitativas, tendo como estratégias utilizadas o estudo de caso, como técnica de coleta de dados a entrevista. Destacaram-se nos resultados, as mulheres como as mais vulneráveis sobre o conflito WFC pela tríplice jornada (trabalho-família-estudo); observou-se ainda, falta de apoio institucional, as pressões das universidades de pesquisa para atender aos rankings, ressaltando-se ainda, as lacunas apresentadas nos estudos sobre o WFC para pesquisas futuras.
\end{abstract}

Palavras-chave: Docência no ensino superior. Conflito Trabalho Família. Universidades.

\section{WORK-FAMILY CONFLICT: NATIONAL AND INTERNATIONAL SCIENTIFIC RESEARCH ON TEACHERS IN HIGHER EDUCATION}

\begin{abstract}
This work aims to analyze how research that deals with the work-family conflict related to higher education teachers in national and international journals is characterized. The research was classified as descriptive and qualitative, having as a technical procedure the systematic review, with a final sample of 20 articles on the Work-Family Conflict (WFC). The analysis occurs through the categorization of Theóphilo and ludícibus (2005) by means of four poles: in the epistemological, the results show that as
\end{abstract}

Perspectivas em Gestão \& Conhecimento, João Pessoa, v. 11, n.1, p. 118-143, jan./abr. 2021. DOI: http://dx.doi.org/10.22478/ufpb.2236-417X.2021v11n1.54773

http://periodicos.ufpb.br/ojs2/index.php/pgc. ISSN: 2236-417X. Publicação sob Licença (cc) EY-Nc-ND 
for the objectives, the comprehensive and evaluative a stand out; in the theoretical pole, the theoretical approaches of Greenhaus and Betel (1985) were verified with more than half of the theoretical approaches used, highlighting the themes of motherhood and gender perception, showing an unfavorable working environment for women; in the methodological pole, hermeneutic and positivist phenomenological researches predominated; at the technical pole, qualitative research prevailed, with case study strategies used as the data collection technique for the interview. In the results, women stood out as the most vulnerable about the WFC conflict for the triple journey (work-family-study); there was also a lack of institutional support, the pressure from research universities to meet the rankings, highlighting if still, the gaps presented in the studies on the WFC for future research.

Keywords: Teaching in higher education. Family work conflict. Universities.

\section{INTRODUÇÃO}

As mudanças nas formas de trabalho, em um mundo digital, têm afetado as relações da vida profissional e familiar, interferindo interna e externamente nas organizações, ocasionado principalmente pela competitividade do mercado de trabalho, que exige cada vez mais um desempenho superior de seus colaboradores na execução de suas práticas laborais e, com isso, o aspecto familiar é deixado em segundo plano, promovendo uma série de problemas para os indivíduos, denominado de conflito trabalho-família (MOREIRA; SILVA HENNING, 2018).

Para conciliar as exigências sempre crescentes das organizações e da família, não se configura em um processo de fácil equalização, ocasionando os conflitos entre trabalho-família e família-trabalho, pois, essa dupla atuação tem deixado um desses papeis prejudicado, tornando-se difícil o equilíbrio, especialmente para os docentes. Greenhaus e Beutell (1985) destacam que o WFC se promove pelas incompatibilidades das dimensões trabalho e família, pois na busca de alcançar sucesso na carreira profissional, o indivíduo tende a se dedicar mais ao trabalho, promovendo o Word-Family Conflict (WFC) conflito-trabalho família (BIACHIM et al., 2019; MOREIRA; SILVA HENNING, 2018; SANTOS; CARDOSO, 2016; CARVALHO et al., 2018; TAKAHASHI et al., 2014; REDDICK et al., 2012; AFRIANTY; BURGESS; ISSA, 2015; FOX; FONSECA; BAO, 2011).

Dentre os setores mais afetados com o WFC, destaca-se o setor educacional, tendo em vista que estudos recentes mostraram que a atividade de ensino no Brasil foi exposta a uma quantidade significativa de pressões, sendo esta categoria uma das mais expostas a vários fatores psicológicos e emocionais. Dentre as diversas profissões, a docência apresenta-se como uma das que, merece outros olhares, sobre a relação trabalho-família. No entendimento de Carloto e Câmara (2014), a docência é a que mais impacta a vida pessoal, pela alta exigência que se requer desse profissional, comprometendo a convivência familiar (CARVALHO et al., 2018, RAFNSDÓTTIR; HEIJSTRA, 2011, HIRAKATA; DANILUK, 2009; ARMENTI. 2004). Destarte, para fins desta pesquisa, o enfoque será direcionado para o WFC no setor educacional.

O regime de trabalho para o docente do ensino superior é muito fatigante, principalmente os que possuem regime de dedicação exclusiva, com 40 horas semanais, com atividades em ensino, pesquisa e extensão, e ainda precisam atender aos requisitos de avaliação do Ministério da Educação e Cultura (MEC), tendo que cumprir metas de produção científica; com isso, as necessidades familiares ficam sacrificadas (CARVALHO et al., 2018; MOREIRA; SILVA HENNING, 2018; QUEVEDO; FLECK; CARMO, 2013).

Por outro lado, a disseminação de políticas que venham amenizar esse conflito no ambiente organizacional é imprescindível, pois a não resolução dos estresses laborais provenientes do WFC podem ocasionar problemas de saúde, principalmente psicológicos, e de outras doenças, que podem acarretar problemas irreversíveis a médio e longo prazo,

Perspectivas em Gestão \& Conhecimento, João Pessoa, v. 11, n.1, p. 118-143, jan./abr. 2021. 
prejudicando as organizações e as famílias (BRAUN; VIERHELLER; OLIVEIRA, 2016; HASLAM; SANDERS; SOFRONOFF, 2013).

Diante das mudanças culturais e organizacionais vigentes em um mundo moderno, em que a visão sistêmica deve prevalecer, pois, se entende que todos os stakeholders devem ser atendidos em suas necessidades, o gerenciamento do WFC passou a ser encarado como uma dimensão a ser superada (O'MEARA; CAMPBEL, 2011). Um corpo emergente de literatura aborda os desafios de equilibrar uma carreira acadêmica com a familiar (BIACHIM et al., 2019; SANTOS; CARDOSO, 2016; CARVALHO et al., 2018; TAKAHASHI et al., 2014; REDDICK et al., 2012; AFRIANTY; BURGESS; ISSA, 2015; FOX; FONSECA; BAO, 2011).

Constatou-se na literatura a existência de revisões sistemáticas e narrativas que tratam sobre o WFC (BANDEIRA; FERREIRA; CABRAL, 2020; VILELA, 2017; VILELA et al., 2018; FEIJÓ et al., 2017; BRAUN; VIERHELLER; OLIVEIRA, 2016). Na configuração desse cenário, emerge a seguinte questão de pesquisa, na busca de se compreender como se promoveram esses estudos: como se caracterizam as pesquisas que tratam do conflito trabalho-família relacionadas aos docentes de nível superior em periódicos nacionais e internacionais? Portanto, o objetivo desta pesquisa é de analisar como se caracterizam as pesquisas que tratam do conflito trabalho-família relacionadas aos docentes de nível superior em periódicos nacionais e internacionais. A análise se dá por meio do uso dos quatro pólos (epistemológico, teórico, metodológico e técnico), desenvolvidos por Paul de Bruyne, Jacques Herman e Marc Schothete, utilizados por Theophilo e ludicíbus (2005), na análise da produção cientifica em Contabilidade em estudos realizados no Brasil.

A proposta dessa pesquisa se torna relevante diante das lacunas existentes na literatura sobre a compilação dos estudos voltados para o WFC na docência superior, tanto em pesquisas nacionais quanto estrangeiras, tendo em vista o escopo direcionado neste artigo, a partir das perspectivas (técnica, epistemológica, teórica e metodológica), que não fora abordada anteriormente. Por isso, por tratar de uma problemática social, a pesquisa proporcionará reflexões pertinentes, especialmente para as instituições de ensino superior, no que diz respeito a promoção de políticas que minimizem o conflito-trabalho-família.

\section{REVISÃO DE LITERATURA}

O WFC, modelo proposto por Greenhaus e Beutell (1985) evidencia-se entre os dois papeis, devido às demandas contraditórias do trabalho-família. Divide-se em dois tipos de conflito, conflito trabalho-família e conflito família-trabalho. Quevedo, Fleck e Carmo (2013) e Noor (2011) evidenciaram implicações negativas dos dois tipos de conflito sobre o bem-estar do indivíduo. As novas aptidões no mundo do trabalho exigidas dos trabalhadores, com a ampliação da dupla carreira dos casais, em que mães com crianças precisam desenvolver suas carreiras, promoveu também as disfunções nas autuações dos papeis, denominando-se o WFC (MOREIRA; SILVA HENNING, 2018; SANTOS; CARDOSO, 2016; TAKAHASHI et al., 2012; GREENHAUS; BEUTELL, 1985).

De acordo com Hardy et al. (2016) e Reddick et al. (2012) o WFC promove riscos e efeitos disfuncionais sobre os trabalhadores, como a depressão e ansiedade e, por esses motivos, a atenção familiar é prejudicada, gerando conflito conjugal, estresse, problemas com os filhos menores, levando a degradação da qualidade de vida do indivíduo. Essas consequências também afetam às organizações, pela redução do comprometimento, insatisfação no trabalho, baixa produtividade e dificuldades de retenção dos trabalhadores na empresa.

No meio acadêmico não é diferente; para os professores que são pais, os compromissos familiares podem ampliar a pressão do aumento da carga de trabalho, configurando-se assim em desafios para equilibrar uma carreira acadêmica com a familiar.

Perspectivas em Gestão \& Conhecimento, João Pessoa, v. 11, n.1, p. 118-143, jan./abr. 2021. 
O'meara e Campbell (2011) e Fox (2011) evidenciam que os professores são afetados pelo WFC e seus efeitos são semelhantes de outras ocupações. Devido à flexibilização do cronograma, eles se habituaram a trabalhar nos fins de semana, e a noite. No entanto, as mulheres não consideram isso ruim, pois podem trabalhar e dedicar-se à família ao mesmo tempo. No estudo de Takahashi et al. (2014) os entrevistados mencionaram que o fato de estarem em casa não significa total dedicação à família. No referido estudo, os autores discorrem acerca das principais teorias em que o WFC é estudado, as quais são encontradas em outras pesquisas e serão destacadas a seguir.

Bandeira, Ferreira e Cabral (2020), evidenciam, quanto à interface do WFC, uma perspectiva enriquecedora, pois no equilíbrio do duplo papel, trabalho e família, o ser humano aglutina ao mesmo tempo, necessidades de tempo e emoção no ambiente de trabalho, em que, nesse resultado, pode existirem interfaces negativa ou positiva, entre as duas esferas. Por sua vez, nos estudos sobre a perspectiva enriquecedora do WFC, Biachim et al. (2019), Reddick et al. (2012), Fox, Fonseca e Bao (2011) e Noor (2011), apontam a interface negativa como perspectiva predominante, pois o envolvimento com o trabalho gera mais conflito do que enriquecimento. Em outra concepção do WFC, Edwards e Rothbard (2000) classificam as categorias em que se encaixam as interações entre as dimensões trabalho-família, sendo: contaminação, compensação, segmentação, escoamento de recursos e conflito, não se configurando como um modelo predominante entre os estudiosos sobre o WFC (TAKAHASHI, et al., 2012).

Por sua vez, Greenhaus e Beutell (1985) ressaltam o entendimento bidirecional do trabalho-família, em que defendem a distinção entre a interferência do profissional no desempenho familiar reciprocamente, em que se destacam a existência de direções distintas, mas ligadas reciprocamente, relacionadas as disfunções dos papeis trabalho-família, onde a primeira está associada a aspectos estruturais no desenvolvimento familiar, os conflitos surgidos na família têm impactos no comportamento e passa a interferir nas atividades laborais (CARVALHO et al., 2018; TAKAHASHI et al., 2014; NOOR, 2011; FOX; FONSECA; BAO, 2011).

A principal abordagem teórica sobre o WFC baseia-se na teoria dos papeis, onde Greenhaus e Beutell $(1985$, p. 77) constituíram a explicação de WFC, como "uma forma de conflito entre papeis em que as pressões do papel dos domínios trabalho-família são mutuamente incompatíveis em algum aspecto". Os confrontos do WFC ocorrem em uma via dupla em sentido contrário; enquanto o WFC é procedente de conflitos entre papeis originados no trabalho que interferem no desempenho de funções familiares, o conflito família-trabalho é gerado no meio familiar e afeta a realização de responsabilidades pertinentes ao trabalho (MOREIRA; SILVA HENNING; 2018; VILELA, 2018; SANTOS; CARDOSO, 2016).

Os pioneiros em estudos sobre WFC, Greenhaus e Beutell (1985) elaboraram um modelo multidimensional para o fenômeno que se tornou hegemônico e continua sendo utilizado como base teórica na maioria dos estudos relacionados. A natureza multidimensional se refere a três dimensões que podem estar na origem do conflito, evidenciando-se, tempo, tensão e comportamento. Na Figura 1, apresenta-se a configuração do modelo para o fenômeno WFC: 
Figura 1- Formas de análise dos conflito trabalho-família

\begin{tabular}{|c|c|c|}
\hline Pressões do trabalho & Incompatibilidade & Pressões da Família \\
\hline $\begin{array}{l}\text { Tempo: horas trabalhadas, } \\
\text { inflexibilidade do horário de } \\
\text { trabalho, trabalhos em turnos } \\
\text { Tensão: conflito de papeis, } \\
\text { ambiguidade de papeis, } \\
\text { atividades extras realizadas } \\
\text { Comportamento: expectativas } \\
\text { de discrição e objetividade }\end{array}$ & $\begin{array}{l}\text { Tempo: o tempo dedicado } \\
\text { a um papel torna difícil } \\
\text { cumprir o outro papel } \\
\text { Tensão: a tensão produzida } \\
\text { por um papel torna difícil } \\
\text { cumprir outro papel } \\
\text { Comportamento: exigido } \\
\text { em um papel torna difícil } \\
\text { cumprir outro papel }\end{array}$ & $\begin{array}{l}\text { Tempo: crianças } \\
\text { pequenas, emprego do } \\
\text { cônjuge, famílias } \\
\text { grandes } \\
\text { Tensão: conflito de } \\
\text { papeis, limitado apoio } \\
\text { do cônjuge } \\
\text { Comportamento: } \\
\text { expectativas de afeição } \\
\text { e abertura }\end{array}$ \\
\hline
\end{tabular}

Fonte: Adaptado de Greenhaus e Beutel (1985)

O conflito baseado no tempo ocorre quando várias pressões de função competem pelo tempo de um indivíduo. Por exemplo, um professor pode precisar produzir relatórios para a instituição dentro de um prazo e isso pode levar algum tempo longe das atividades da família (MOREIRA; SILVA HENNING, 2018; TAKAHASHI, et al., 2014; FOX; FONSECA; BAO, 2011). Na fonte de conflito tempo, evidencia-se aquele que o trabalhador destina para o seu trabalho e ainda os períodos anormais, como a carga excessiva de muitas horas de labor, sendo apontadas pelo aumento do conflito. Em pesquisa realizada por Takahashi et al. (2012), com docentes, evidenciou-se que, o fator tempo é o mais percebido pelos homens e constatou-se que o WFC se mostrou elevado para as mulheres, onde se observa que, com restrição de tempo pelo labor, o envolvimento familiar é prejudicado nas suas necessidades. Coadunam com esse entendimento O'meara e Campbel (2011); Rafndóttir e Heijstra (2011); Hardy et al. (2016); Wendel e Ward (2006), sendo consensual que as mulheres são as mais atingidas pelo WFC.

Os múltiplos papeis desempenhados podem competir pelo tempo do trabalhador, já que o tempo exercido em tarefas de um papel, não se pode dedicar da mesma forma ao outro papel. Este é um conflito se desenvolve à proporção que as pessoas desempenham mais de um papel, consequentemente, não terão energia para atender todas as demandas que são exigidas pelos vários papéis, promovendo em pressões prejudiciais no desempenho das suas funções. Dessa forma, quanto mais se dedica a um papel, menor será o tempo e energia disponível para gastar em outro papel (MOREIRA; SILVA HENNING; 2018; HASLAM; SANDERS; SOFRONOFF, 2013; NOOR, 2011; GREENHAUS; BEUTELL, 1985).

Na segunda fonte do WFC, a tensão é produzida pelo desempenho na função e ocorre quando os sintomas de estresse criados, dificultam cumprir as exigências de outro papel, afetando assim o indivíduo no desempenho individual do trabalho ou da família. Por exemplo, um professor pode se estressar ao gerenciar o comportamento difícil de alguns alunos e estar cansado e menos tolerante com o comportamento dos seus filhos em casa; o conflito existe quando a tensão em cumprir uma função compromete a posição de outro papel, promovendo a incompatibilidade, já que a tensão promovida por um atrapalha a realização das demandas do outro papel (BANDEIRA; FERREIRA; CABRAL, 2020; VILELA; LOURENÇO, 2017;TAKAHASHI et al., 2014; QUEVEDO; FLECK; CARMO, 2013; NOOR, 2011; FOX; FONSECA; BAO, 2011; GREENHAUS; BEUTELL, 1985).

Por fim, conflito baseado em comportamento refere-se a padrões de comportamento associados a uma função que são incompatíveis com padrões de comportamento ligados a vida pessoal. Por exemplo, quando as crianças se machucam, seus pais podem confortá-las com abraços e beijos, mas isso é inadequado quando o mesmo pai está no papel de professor no ambiente acadêmico (FEIJÓ et al., 2017; FOX, 2005; GREENHAUS; BEUTELL, 1985). O

Perspectivas em Gestão \& Conhecimento, João Pessoa, v. 11, n.1, p. 118-143, jan./abr. 2021. 
comportamento, também abrange a incoerência existente nos comportamentos estabelecidos para o trabalhador (rigidez, profissionalismo e imparcialidade), e ordenados para o trabalhador na família atenção. Ternura e sensibilidade), o que por suposição contribui para a interação conflituosa trabalho-família (VILELA, 2018; HASLAM; SANDERS; SOFRONOFF, 2013; GREENHAUS; BEUTELL, 1985).

Na sequência, apresentam-se estudos recentes que foram realizados, através dos tipos de revisões sistemáticas, sobre o WFC. No Quadro 1 apresentam-se os principais aspectos de estudos relacionados sobre o WFC:

Quadro 1 - Estudos de trabalhos semelhantes

\begin{tabular}{|c|c|c|}
\hline Autores & Objetivo & Resultados \\
\hline $\begin{array}{l}\text { Bandeira, } \\
\text { Ferreira } \\
\text { e Cabral } \\
(2020)\end{array}$ & $\begin{array}{c}\text { A pesquisa objetivou a apresentação da } \\
\text { produção em periódicos internacionais } \\
\text { sobre o WFC por meio do modelo } \\
\text { quadripolar. }\end{array}$ & $\begin{array}{l}\text { Como principias achados, destacou-se no } \\
\text { polo epistemológico, apresentação de } \\
\text { objetivos robustos, com apresentação de } \\
\text { hipóteses, destacando-se a abordagem } \\
\text { tridimensional de Greenhaus e Geutell, } \\
\text { ainda, prevaleceu a abordagem } \\
\text { positivista, com estudos quantitativos, } \\
\text { com estratégia survey. }\end{array}$ \\
\hline $\begin{array}{l}\text { Vilela e } \\
\text { Lourenço } \\
(2017)\end{array}$ & $\begin{array}{c}\text { Teve como objetivo promover uma análise } \\
\text { das políticas ofertadas para amenizar o } \\
\text { WFC, verificando a diferenciação e } \\
\text { utilização entre países, considerando a } \\
\text { questão de gênero. }\end{array}$ & $\begin{array}{l}\text { Constatou-se que as políticas públicas ou } \\
\text { privadas, não conseguem atingir o WFC, } \\
\text { pois existem pré-conceitos em usá-las, } \\
\text { assim como, falta de incentivo das } \\
\text { instituições, e na questão de gênero é } \\
\text { percebida de forma diferente, com um } \\
\text { viés de gênero para o feminino, por ser } \\
\text { mais vulnerável ao WFC. }\end{array}$ \\
\hline $\begin{array}{l}\text { Feijó et al. } \\
\text { (2017) }\end{array}$ & $\begin{array}{c}\text { Objetivou através de uma revisão } \\
\text { bibliográfica em periódicos nacionais, } \\
\text { apresentar uma comparação dos estudos } \\
\text { relacionados ao WFC. }\end{array}$ & $\begin{array}{l}\text { Evidenciaram que a redução do WFC nos } \\
\text { estudos comparados em pesquisa no } \\
\text { Brasil, estão dependentes da relação } \\
\text { organização-trabalhador, que vislumbrem } \\
\text { e promovam meios para amenizar o WFC } \\
\text { no ambiente laboral. }\end{array}$ \\
\hline Vilela (2018) & $\begin{array}{c}\text { Através de uma revisão sistemática } \\
\text { objetivou analisar a produção científica } \\
\text { nacional do WFC, em três bases de dados. }\end{array}$ & $\begin{array}{l}\text { Como principais achados destacaram-se: } \\
\text { predominância de periódicos da area de } \\
\text { administração, com objetivos distintos, e } \\
\text { amostras diversificadas, a abordagem } \\
\text { metodológica qualitativa, que mais se } \\
\text { evidenciou, destacando a mulher como a } \\
\text { mais afligida pelo WFC pelo cuidado com } \\
\text { os filhos. }\end{array}$ \\
\hline $\begin{array}{l}\text { Braun, } \\
\text { Vierheller e } \\
\text { Oliveira } \\
\text { (2016) }\end{array}$ & $\begin{array}{l}\text { Realizar uma análise do conflito trabalho- } \\
\text { família com executivos em publicações } \\
\text { nacionais e internacionais no período de } \\
2009 \text { a } 2014 \text { em três bases de dados. }\end{array}$ & $\begin{array}{c}\text { Os resultados evidenciaram estudos } \\
\text { quantitativos, nos Estados Unidos, na } \\
\text { area de ciências extas, destacou-se a } \\
\text { escassez de estudos para as organizações } \\
\text { amenizarem o WFC. }\end{array}$ \\
\hline $\begin{array}{l}\text { Vilela et al. } \\
\qquad(2018)\end{array}$ & $\begin{array}{l}\text { Consistiu em evidenciar o cenário da } \\
\text { produção científica sobre o WFC na Web } \\
\text { of Science entre } 2007 \text { e } 2016 \text {. }\end{array}$ & $\begin{array}{c}\text { Destacaram-se, a constatação no } \\
\text { aumento de publicações sobre o WFC em } \\
\text { inglês, principalmente, em psicologia e } \\
\text { Economia, onde apresentou } 15 \text { hot topics } \\
\text { sobre o WFC. }\end{array}$ \\
\hline
\end{tabular}

Fonte: Elaborado pelos autores (2020) 
Um dos pontos convergentes nesses estudos se referem a desigualdade de gênero, com relação ao WFC, em que a mulher é a mais impactada, sendo o ambiente laboral desfavorável para o feminino (VILELA; LOURENÇO, 2017). O desequilíbrio da divisão de tarefas entre homens e mulheres no ambiente doméstico é ainda evidenciado por Vilela (2018) e Feijó et al. (2017); e nos hot tópicos apresentados por Vilela et al. (2018) as diferenças de gênero se elenca entre um dos principais tópicos relacionados sobre WFC.

Constatou-se a predominância de estudos quantitativos sobre o tema, sendo estas pesquisas do tipo survey, com dados coletados por questionários, sendo a escala de Carlson, Kacmar e Willians (2000) a mais predominante nos estudos analisados; destacando-se como áreas mais estudadas: hotelaria e turismo, gestão de negócios, psicologia e economia de negócios (BANDEIRA; FERREIRA; CABRAL, 2020; FEIJÓ et al., 2017; BRAUN; VIERHELLER; OLIVEIRA, 2016).

Com relação às políticas para amenizar o WFC, Vilela e Lourenço (2018) constataram que as mesmas não são efetivadas por inibição dos funcionários, com medo de prejudicar suas carreiras e por falta de incentivos das organizações para que essas práticas sejam disseminadas. Nessa mesma ótica, Feijó et al. (2017) apontam a necessidade de aceitação e colaboração dos gestores para efetivação de políticas para amenizar esse conflito.

Outro ponto que foi evidenciado nos estudos realizados é a utilização de arranjos flexíveis de trabalho como o meio mais citado para se amenizar o conflito trabalho-família, pois esse mecanismo permite encontrar o equilíbrio das necessidades da família e do trabalho, em que o trabalhador, com esse problema resolvido, conseguiria desempenhar com maior eficiência as suas tarefas laborais (BANDEIRA; FERREIRA; CABRAL, 2020; VILELA, et al., 2018; FEIJÓ et al., 2017; VILELA; LOURENÇO, 2017; BRAUN; VIERHELLER; OLIVEIRA, 2016).

\section{PROCEDIMENTOS METODOLÓGICOS}

Quanto a forma de abordagem, a pesquisa é qualitativa, em que se busca compreender o detalhamento de aspectos diferentes dos fenômenos com maior nível de profundidade; e quanto ao objetivo geral é de caráter descritivo, pois procura descrever as características de uma determinada população, o procedimento técnico utilizado é o bibliométrico, pois se utiliza de material já publicado, de artigos de periódicos (via eletrônico) e como técnica analítica para à aquisição de dados, utilizou-se da análise sistemática e de conteúdo, técnicas essas escolhidas para descreverem os aspectos do conflito trabalho-família relacionados com docentes de nível superior (Gil, 2010; MARCONI; LAKATOS, 2009; BEUREN, 2006).

Em revisões sistemáticas, procura-se responder de forma aprofundada os questionamentos (BRAUN; VIERHELLER; OLIVEIRA, 2016). O objetivo da pesquisa reside em analisar como se caracterizam as pesquisas que tratam do conflito trabalho-família relacionadas aos docentes de nível superior em periódicos nacionais e internacionais, nos polos técnico, metodológico, epistemológico e teórico dos estudos relacionados ao WFC. Para tanto, realizou-se a pesquisa em junho de 2020 sobre o tema na base de dados 'Scopus' e periódicos da Coordenação de Aperfeiçoamento de Pessoal de Nível Superior (CAPES), que são bases de dados robusta de resumos e citações de literatura revisada por pares, com ferramentas bibliométricas para acompanhar, analisar e visualizar pesquisas.

Dessa forma, o procedimento de busca dos artigos se estabeleceu no website da base de dados Scopus e periódicos Capes, realizando-se a busca através das palavras-chave 'workfamily conflict' e 'teacher' nos campos título do artigo, resumo e palavras-chave. Inicialmente, obteve-se 144 resultados. No quadro 2 apresenta-se a sistemática utilizada para seleção da amostra.

Perspectivas em Gestão \& Conhecimento, João Pessoa, v. 11, n.1, p. 118-143, jan./abr. 2021. 
Quadro 2 - Sistemática para realizar a amostra do estudo

\begin{tabular}{|c|c|c|}
\hline Etapa & $\begin{array}{c}\text { Quant. de } \\
\text { Artigos }\end{array}$ & \multicolumn{1}{c|}{ Critérios } \\
\hline $\begin{array}{c}\text { 10 } \\
\text { Passo }\end{array}$ & $\begin{array}{c}\mathbf{1 4 4} \\
\text { artigos }\end{array}$ & $\begin{array}{l}\text { Critério de busca: base de dados Scopus e periódicos capes, buscou-se na } \\
\text { combinação das palavras-chaves: 'work-family conflict' e 'teacher' nos campos } \\
\text { título do artigo, resumo e palavras-chave. }\end{array}$ \\
\hline $\begin{array}{c}\text { 20 } \\
\text { Passo }\end{array}$ & $\mathbf{4 3}$ artigos & $\begin{array}{l}\text { Critério de Seleção: Período de 20 anos: 2000 a 2020; area temática: ciências } \\
\text { sociais aplicadas; artigo científico completo; Idioma: português e inglês. Nesta } \\
\text { fase, 101 trabalhos foram excluídos e após a leitura o assunto deveria ser: o } \\
\text { WFC relacionado a docentes de nível superior }\end{array}$ \\
3o & $\mathbf{2 0}$ artigos & $\begin{array}{l}\text { Critérios de exclusão: não abordar o WFC com docentes de nível superior; não } \\
\text { incluir docentes na amostra; 43 trabalhos e após a leitura do título, resumo e } \\
\text { palavras-chave; 23 trabalhos excluídos após a leitura e análise dos objetivos, } \\
\text { metodologia e conclusões. }\end{array}$ \\
\hline
\end{tabular}

Fonte: Elaborada pelos autores (2020)

Estabeleceu-se os seguintes critérios para selecionar os artigos: o período de 20 anos, de 2000 a 2020, que proporciona uma quantidade razoável de trabalhos para avaliar a produção acadêmica; a área de conhecimento ciências sociais aplicadas, das subáreas temáticas, do tipo de publicação (artigo), do idioma português e inglês, escolhido por abranger trabalhos de maior amplitude. Após o estabelecimento desses filtros, a amostra final reúne 20 artigos, que se processaram de acordo com o Quadro 2. Destaca-se que no 10 passo foram lidos os títulos, resumos e palavras-chave dos 144 artigos, a fim de determinar as pesquisas que estavam em concordância com o presente estudo; no 20 passo foram lidas as metodologias dos artigos, onde 101 artigos foram excluídos, por fugirem do escopo do estudo; no 3으 passo, com a leitura mais aprofundada dos textos, excluíram-se 23 artigos, por se referirem ao WFC, mas de temáticas diferentes.

A consolidação da amostra se deu nesses três passos, finalizou-se com à análise dos 20 artigos na íntegra. Para a análise sistemática desse estudo, utilizou-se das categorias de análise evidenciadas por Theóphilo e ludicíbus (2005), desenvolvendo-se através dos polos, técnico, metodológico epistemológico e teórico. O polo epistemológico se apresenta como fundamento da descoberta, onde se realiza através do exame do processo dos objetos e da análise de validação e estabelecimento dos procedimentos científicos, denominada lógica da prova, e através da análise da problematização ou dos objetivos dos estudos que são igualmente; para delinear os objetivos utilizou-se também da categorização desenvolvida por Larocca, Rosso e Souza (2005), que em sua pesquisa estabeleceram os objetivos em quatro categorias: compreensivos, avaliativos, propósitos e descritivos.

O objetivo do polo teórico é o da reconstrução conceitual das estruturas objetivas dos fenômenos, de modo a compreendê-los e explicá-los; dessa forma, separaram-se as pesquisas em (i) positivista, onde, buscou a explicação do 'o que é', ao invés do que deve ser, onde procura demonstrar as razões da prática observada, para se descrever o funcionamento da realidade; (ii) o normativo, estabelecendo-se regras de como se deve ser feita a coisa, com característica descritiva; e (iii) teoria que foi utilizada como base para a pesquisa (THEÓPHILO; IUDíCIBUS, 2005).

O polo metodológico têm como objetivo o aperfeiçoamento dos procedimentos e critérios de como foi realizado o estudo, classificando-se em: (i) empirista, que possui como características a observação da realidade e baseiam-se em pressupostos que sustentam a busca da superação da subjetividade; (ii) positivista, distingue-se pela procura da elucidação dos fatos a partir das suas relações, que possam ser comprovados cientificamente; (iii) sistêmica, que apresenta como característica a visão do objeto como um sistema e a compreensão de causa fundamentada na influência mútua entre os construtos; e (iv)

Perspectivas em Gestão \& Conhecimento, João Pessoa, v. 11, n.1, p. 118-143, jan./abr. 2021. 
fenomenológica, que se preocupa com a descrição direta da experiência, tal como ela é; a realidade é construída pelo resultado da pesquisa (THEÓPHILO; IUDíCIBUS, 2005).

Por fim, o polo técnico se configura com a coleta e análise dos dados. Para as ciências sociais aplicadas, utiliza-se o termo estratégias de pesquisa para as diferentes maneiras de classificar um estudo. Assim, foram evidenciadas as técnicas de coleta de dados nos artigos: pesquisa bibliográfica, entrevista, questionário, estudo de caso, análise de conteúdo, pesquisaação, observação e outras que possam se evidenciar nesse estudo (THEÓPHILO; IUDíCIBUS, 2005). A compilação e categorização dos dados foram organizados em planilhas eletrônicas no pacote do software Microsoft Office Excel. A utilização de filtros e tabelas dinâmicas proporcionaram a análise de pontos específicos da amostra, assim como, a intersecção dos dados na busca do aprofundamento da análise.

\section{ANÁLISE E DISCUSSÃO DOS RESULTADOS}

Conforme detalhado na metodologia, com a amostra final, aprimorou-se a leitura acurada e a compilação dos dados, para se processar a análise sistemática, em que foram examinados os polos, técnico, metodológico, teórico e epistemológico com estudos sobre o WFC com docentes de nível superior em publicações nacionais e internacionais.

\subsection{Polo epistemológico}

Nesta subseção, optou-se por analisar os objetivos das pesquisas. Assim, o estabelecimento do polo epistemológico desempenha um acompanhamento crítico da pesquisa e a problemática de investigação é delineada em uma conotação científica, passandose as descrever as concepções como cientificidade, causalidade e validação dos estudos (THEÓPHILO; ÍUDICIBUS, 2005). No Quadro 3, evidenciam-se os objetivos principais dos 20 estudos que foram analisados:

Quadro 3 - Objetivo dos estudos analisados sobre conflito trabalho família com docentes

\begin{tabular}{|c|l|}
\hline Autores & \multicolumn{1}{c|}{ Objetivo } \\
\hline $\begin{array}{c}\text { Bianchim et al. } \\
(2019)\end{array}$ & $\begin{array}{l}\text { Analisar a configuração das interfaces entre trabalho e família pro meio da } \\
\text { concepção dos professores de IES. }\end{array}$ \\
\hline $\begin{array}{c}\text { Moreira, Silva e } \\
\text { Henning (2018) }\end{array}$ & $\begin{array}{l}\text { Identificar a influência dos aspectos do WFC e comprometimento com a docência } \\
\text { na compreensão de êxito na carreira de docentes mulheres. }\end{array}$ \\
\hline $\begin{array}{c}\text { Carvalho et al. } \\
(2018)\end{array}$ & $\begin{array}{l}\text { Investigar a invariância da medida entre os sexos masculino e feminino, } \\
\text { relativamente à ITF e IFT, em docentes do ensino superior em Portugal }\end{array}$ \\
\hline $\begin{array}{c}\text { Santos e } \\
\text { Cardoso (2016) }\end{array}$ & $\begin{array}{l}\text { Discutir sua influência no nível de trabalho-família conflito e a eficácia das políticas } \\
\text { da família e trabalho portugueses. }\end{array}$ \\
\hline $\begin{array}{c}\text { Afrianty, } \\
\text { Burgess e Issa } \\
(2016)\end{array}$ & $\begin{array}{l}\text { Examinar a eficácia de programas voltados para a família no local de trabalho no } \\
\text { setor de ensino superior da Indonésia. O foco é o impacto que esses programas têm } \\
\text { no conflito familiar do trabalho dos funcionários. }\end{array}$ \\
\hline $\begin{array}{c}\text { Hard et al. } \\
(2016)\end{array}$ & $\begin{array}{l}\text { explorar os impactos que os pais e responsabilidades de cuidados primários com os } \\
\text { filhos sobre carreiras acadêmicas. }\end{array}$ \\
\hline $\begin{array}{c}\text { Takahashi } \text { et al. } \\
(2014)\end{array}$ & $\begin{array}{l}\text { Analisar como os professores, atuando na pós-graduação programas de gestão em } \\
\text { três instituições de ensino superior lidam com os conflitos trabalho-família. }\end{array}$ \\
\hline $\begin{array}{c}\text { Quevedo, Fleck } \\
\text { e Carmo (2013) }\end{array}$ & $\begin{array}{l}\text { Investigar a conduta dos professores que exercem o enquadramento funcional de } \\
\text { dedicação exclusiva na UNIPAMPA, por meio dos vieses: gestão do tempo de } \\
\text { trabalho e tempo livre. }\end{array}$ \\
\hline $\begin{array}{c}\text { Takahashi et al. } \\
\text { (2012) }\end{array}$ & $\begin{array}{l}\text { Analisar as competências empreendedoras e conflito trabalho-família em } \\
\text { professores de programas de mestrado e doutorado em administração. }\end{array}$ \\
\hline Reddick et al. & Analisar o corpo docente masculino com crianças menores e o enfrentamento do \\
\hline
\end{tabular}

Perspectivas em Gestão \& Conhecimento, João Pessoa, v. 11, n.1, p. 118-143, jan./abr. 2021. 


\begin{tabular}{|c|c|}
\hline$(2012)$ & conflito trabalho-família. \\
\hline $\begin{array}{l}\text { Fox. Fonseca e } \\
\text { Bao (2011) }\end{array}$ & $\begin{array}{l}\text { Abordar conflitos entre trabalho-família, através de relatos de cientistas } \\
\text { acadêmicos em dados coletados sistematicamente em campos de estudo em nove } \\
\text { universidades de pesquisa dos EUA. }\end{array}$ \\
\hline $\begin{array}{c}\text { O'meara e } \\
\text { Campbel (2011) }\end{array}$ & $\begin{array}{l}\text { Analisar as práticas institucionais sobre casos relacionados ao conflito trabalho- } \\
\text { família. }\end{array}$ \\
\hline $\begin{array}{l}\text { Rafnsdóttir e } \\
\text { Heijstra (2011) }\end{array}$ & $\begin{array}{l}\text { Analisar a estruturação do tempo entre os acadêmicos da Islândia, como eles } \\
\text { organizam e conciliam sua vida profissional e familiar e se o gênero é um fator } \\
\text { definidor contexto. }\end{array}$ \\
\hline Noor ( & $\begin{array}{l}\text { Examinar a relação entre satisfação percebida no equilíbrio entre vida profissional e } \\
\text { acadêmica de Instituições públicas de ensino superior da Malásia e suas intenções } \\
\text { de deixar a organização. }\end{array}$ \\
\hline $\begin{array}{c}\text { Hirakata e } \\
\text { Daniluk (2009) }\end{array}$ & $\begin{array}{l}\text { Estudar o caso das mulheres que tentam equilibrar as demandas da maternidade e } \\
\text { uma carreira acadêmica. }\end{array}$ \\
\hline $\begin{array}{l}\text { Doherty e } \\
\text { Manfredi } \\
(2006)\end{array}$ & $\begin{array}{l}\text { Mostrar até que ponto uma abordagem da pesquisa-ação, pode ser usada para } \\
\text { analisar as políticas e práticas de equilíbrio na vida profissional em um contexto } \\
\text { universitário. }\end{array}$ \\
\hline $\begin{array}{l}\text { Wendel e Ward } \\
\qquad(2006)\end{array}$ & $\begin{array}{l}\text { Explorar a interface entre trabalho e família em diferentes tipos de instituições de } \\
\text { ensino superior, na perspectiva mulheres com filhos pequenos. }\end{array}$ \\
\hline Fox (2005) & $\begin{array}{l}\text { Analisar a relação entre casamento, filhos e produtividade das publicações para } \\
\text { mulheres, em comparação com os homens, na ciência acadêmica. }\end{array}$ \\
\hline $\begin{array}{l}\text { Fothergill e } \\
\text { Feltey (2004) }\end{array}$ & $\begin{array}{l}\text { Analisar a influência dos filhos na carreira acadêmica de docentes em universidades } \\
\text { dos Estados Unidos. }\end{array}$ \\
\hline Armenti (2004) & $\begin{array}{l}\text { Explorar as interconexões entre os aspectos pessoais e profissionais das mulheres e } \\
\text { suas vidas familiares. }\end{array}$ \\
\hline
\end{tabular}

Fonte: Elaborado pelos autores (2020)

Destaca-se que na maioria dos artigos internacionais não se apresenta a questão 'problema', mas, as hipóteses ou pressupostos, são construídos na revisão de literatura, em que se argumenta o motivo e objetivo da pesquisa que se pretende desenvolver, por isso não serão apresentadas as problematizações, tendo em vista que, 13 dos estudos não apresentaram a problematização, a qual foi inserida na discussão teórica, em que, através do aprofundamento do tema, se contextualiza o objetivo principal do estudo, pois, na concepção de Theóphilo e ludicíbus (2005), esse processo é igualmente válido. Essa configuração coaduna com os resultados constatados por Bandeira, Ferreira e Cabral (2019), em estudos sobre conflito trabalho-família.

Entre os 20 artigos selecionados, em nove deles, não havia a definição específica do termo 'conflito trabalho-família' em seus objetivos, mas tratavam do WFC nos seguintes tópicos: Fox (2005) relação de casamento, filhos e academia; Doherty e Manfredi (2006) vida pessoal e contexto acadêmico, Hard et al. (2016) cuidados com filhos e carreira acadêmica; Quevedo, Fleck e Carmo (2013) regime de dedicação exclusiva e tempo livre; Noor (2011), equilíbrio entre vida pessoal e acadêmica; Hirakata e Daniluk (2009) família e carreira acadêmica; Wendel e Ward (2006) maternidade e carreira acadêmica; Fothergill e Feltey (2004) filhos e carreira acadêmica.

Para realizar a análise da formulação dos objetivos de pesquisa, recorreu-se a Larocca, Rosso e Souza (2005), que em sua pesquisa estabeleceram os objetivos em quatro categorias: compreensivos, avaliativos, propósitos e descritivos, em que, após análise do Quadro 3, realizou-se a categorização dos objetivos desse estudo, sintetizados na Tabela 1: 
Tabela 1 - Categorias de objetivos, frequência e incidência

\begin{tabular}{ccc}
\hline Tipos de Objetivos & $\mathbf{F i}$ & $\%$ \\
\hline Compreensivos & 6 & 30 \\
Avaliativos & 6 & 30 \\
Descritivos & 5 & 25 \\
Propositivos & 3 & 15 \\
\hline Total & $\mathbf{2 0}$ & $\mathbf{1 0 0}$ \\
\hline
\end{tabular}

Fonte: Elaborada pelos autores (2020)

Conforme Tabela 1, observa-se em $30 \%$ dos artigos analisados, os objetivos são do tipo compreensivos, em que se buscaram a interpretação, percepção da totalidade, formação de valores, narrações dos sentidos, compreendendo-se uma dada realidade ou problema amplamente. No geral, os estudos com objetivos compreensivos utilizaram os verbos compreender, analisar, refletir, investigar, discutir e caracterizar, apontando pistas de propósitos compreensivos. Nesse entendimento categórico, enquadraram-se os estudos de Biachim et al. (2019), Quevedo, Fleck e Carmo (2013), O'meara e Campbell (2011), Doherty e Manfredi (2006), Armenti (2004) e Fortbergil e Felltey (2004), os quais buscaram compreender como determinadas variáveis se reverberam sobre o WFC em um contexto mais amplo.

No que the concerne, os objetivos avaliativos (30\%), buscaram a interpretação, formação de juízo, através de propostas de mudanças, com descrição dos fenômenos. Identificaram-se esses objetivos por examinar repercussões e acuidade das proposições derivadas da análise crítica. Enquadram-se nessa categoria os estudos de Santos e Cardoso (2016), Afrianty, Burgess e Issa (2016), Takahashi et al. (2012), Noor (2011), Rafndóottir e Heijstra (2011) e Hirakata e Daniluk (2009). Nesse contexto, os estudos relacionados com o WFC que buscaram a avaliação de situações que envolvem os docentes e suas famílias, apresentaram suas opiniões e propostas com o intuito de amenizar o WFC.

Em terceiro, destacam-se os objetivos descritivos (25\%), que buscaram a percepção da totalidade, com a exposição de achados e elaboração de propostas com formação de juízos. Estes, foram identificados pelos verbos traçar, identificar, conhecer, analisar a forma, investigar de que maneira, destacando-se os estudos de Moreira e Silva (2018), Carvalho et al. (2018), Takahashi et al. (2018), Reddick, Rochlen e Grasso (2012) e Fox, Fonseca e Bao (2011). Esses objetivos buscaram promover uma análise do conflito trabalho-família com interpretação dos resultados e opiniões dos autores.

Os objetivos propositivos (15\%) dos estudos, expuseram os achados com formação de juízo de valor, onde se busca a descrição dos fenômenos para apresentar propostas de mudanças. Podem ser identificados com os construtos de contribuir para buscar ou levantar alternativas, propor, definir e subsidiar. Nessa ótica, identificaram-se os estudos de Hardy et al. (2016) e Wendel e Ward (2006), constatando-se que os objetivos nessa categoria buscaram conhecer o fenômeno e as variáveis do WFC e apresentaram propostas para amenizar o WFC.

$\mathrm{Na}$ análise dos objetivos, não se verificaram objetivos com busca de uma resposta negativa ou positiva, assim como objetivos evidenciando quais características devem ter um modelo que atenda a determinado propósito, e ainda, não se verificaram questão de valor, onde perguntaria se algo é bom ou ruim, ou se uma ou mais coisas dentre duas ou mais coisas, é melhor ou pior que a outra. Construtos como esses citados não se verificaram nos objetivos analisados nesse estudo sobre o WFC relacionados a docentes de nível superior (LAROCCA; ROSSO; SOUZA, 2005; THEÓPHILO; IUDÍCIBUS, 2005). 


\subsection{Polo teórico}

Nesse polo, avaliou-se a postura teórica dos artigos e a utilização de teorias de base nas pesquisas, uma vez que as teorias orientam a busca dos fatos, estabelecendo critérios para observação, buscando respostas às questões e orientando os achados de uma pesquisa, e ainda, buscou-se verificar as temáticas utilizadas (THEÓPHILO; IUDíCIBUS, 2005). Com relação à análise das abordagens teóricas e temáticas, elaborou-se a Tabela 2.

Tabela 2 - Teorias e temáticas utilizadas nos estudos

\begin{tabular}{|c|c|c|c|c|c|}
\hline Abordagens Teóricas & $\mathbf{F i}$ & $\%$ & Temáticas & $\mathbf{F i}$ & $\%$ \\
\hline Teoria dos papeis & 5 & 25 & Maternidade na docência & 6 & 30 \\
\hline Teoria da bidirecionalidade & 3 & 15 & Percepção entre gênero & 4 & 20 \\
\hline Modelo multidimensional & 3 & 15 & Políticas Trabalho-família & 3 & 15 \\
\hline Não utilizou teoria & 3 & 15 & Docência WFC & 2 & 10 \\
\hline Teoria do transbordamento & 2 & 10 & $\begin{array}{c}\text { Competência } \\
\text { empreendedoras }\end{array}$ & 1 & 5 \\
\hline Sociológica & 1 & 5 & Produção científica WFC & 1 & 5 \\
\hline Feminismo cultural & 1 & 5 & Dedicação exclusiva WFC & 1 & 5 \\
\hline $\begin{array}{l}\text { Teoria da conservação de } \\
\text { recurso }\end{array}$ & 1 & 5 & Comparação de IES & 1 & 5 \\
\hline Teoria do enriquecimento & 1 & 5 & Paternidade na docência & 1 & 5 \\
\hline Total & 20 & 100 & Total & 20 & 100 \\
\hline
\end{tabular}

Nos artigos da amostra, encontraram-se no polo teórico uma breve revisão da literatura que sustentam as hipóteses ou pressupostos levantados. Dos artigos analisados, 11 baseiam-se em discussões que envolvem as abordagens teóricas de Greenhaus e Beutell (1985), com a teoria dos papeis (25\%), do modelo multidimensional (15\%) e da bidirecionalidade do conflito (15\%), sendo os três aspectos complementares (MOREIRA; SILVA, 2018; CARVALHO et al., 2018; HARDY et al., 2016; TAKAHASHI et al., 2014; TAKAHASHI et al., 2012; FOX, 2011).

Além das teorias já consolidadas, constatou-se um estudo de Biachim et al. (2019), que estudaram a interface do WFC, na percepção de docentes de instituições públicas e privadas, através da teoria do enriquecimento, desenvolvida por Greenhaus e Powell (2006) e que envolve a perspectiva da facilitação, em oposição ao conflito de papeis, como possível resultado da relação entre trabalho e família.

Em outros 6 estudos, são evidenciadas teorias diversas. Afrianty, Burgess e Issa (2016) utilizaram a teoria da conservação dos recursos para examinar a eficácia dos programas de apoio às famílias dos docentes na Indonésia. Hardy et al. (2016) e Reddick et al. (2012) utilizaram a teoria da fronteira e teoria do transbordamento (WFC) para verificar o conflito trabalho-família com docentes (homens) com filhos menores. Armenti (2004), por sua vez, utilizou de teorias relacionadas ao feminismo para examinar a progressão na carreira docente de mulheres com filhos em uma universidade canadense. O'meara e Campbel (2011), guiaramse pelo conceito sociológico de agência sobre mulheres em universidades de pesquisa no equilíbrio Trabalho-Família.

Por sua vez, 3 estudos não utilizaram teorias nas suas pesquisas, mas desenvolveram um aprofundamento teórico sobre os temas em análise e cruzamento de informações de estudos já realizados para contextualizar o objetivo das pesquisas. Fox (2005) analisou a relação entre casamento, filhos em relação aos homens em programas de doutorado nos EUA; Hirakata e Daniluk (2009) estudaram o caso de mulheres na busca do equilíbrio entre

Perspectivas em Gestão \& Conhecimento, João Pessoa, v. 11, n.1, p. 118-143, jan./abr. 2021. 
maternidade e carreira acadêmica; e Fothergill e Feltey (2004) examinaram a influência dos filhos na carreira acadêmica de mulheres em universidades americanas.

Ainda na Tabela 2, foram evidenciadas as temáticas dos 20 artigos analisados, constatando-se que $30 \%$ se referem a maternidade na academia, $20 \%$ sobre percepção de gênero e $15 \%$ relacionados a políticas. Evidenciou-se a maternidade como tema predominante nos estudos, assim como as percepções de gênero, pois constataram a mulher como a mais afligida pelo WFC, pela tríplice jornada (trabalho-família-estudos) (CARVALHO et al., 2018; TAKAHASHI, et al.,2014; FOTBERGIL; FELLTEY, 2004; HIRAKATA; DUNKLEY, 2009).

\subsection{Polo metodológico}

O polo metodológico, segundo Theóphilo e ludícibus (2005) tem como objetivo o aperfeiçoamento dos procedimentos e critérios usados para desenvolver a pesquisa, ou seja, como foi realizado o estudo, na Tabela 3, demonstram-se as frequências das abordagens metodológicas verificadas nos estudos:

Tabela 3 - Abordagem metodológica da produção científica

\begin{tabular}{ccc}
\hline Abordagem Metodológica & $\mathbf{F i}$ & $\mathbf{\%}$ \\
\hline Fenomenológica Hermenêutica & 8 & $40 \%$ \\
Positivista & 6 & $30 \%$ \\
Fenomenológica Descritiva & 4 & $20 \%$ \\
Empírica & 2 & $10 \%$ \\
\hline Total & $\mathbf{2 0}$ & $\mathbf{1 0 0 \%}$ \\
\hline
\end{tabular}

Fonte: Elaborado pelos autores (2020)

As abordagens metodológicas nos artigos analisados foram evidenciadas através de análise do objeto de estudo e entendimento dos métodos utilizados, pois em alguns estudos não é clara a abordagem metodológica para se enquadrar na escala de Theóphilo e ludícibus (2005) e, por esse motivo, fez-se necessária uma análise detalhada.

Conforme Tabela 3, a abordagem fenomenológica hermenêutica foi a que mais se destacou, presente em $40 \%$ dos estudos, onde se buscou o significado atribuído aos sujeitos e suas experiências reais, relacionados ao WFC na docência, em que através da análise dos fatos, busca-se compreender a coisa como ela é. Os estudos se realizam através de entrevistas em profundidade e são tratados com análise de conteúdo, promovendo a interpretação dos dados com inferência dos autores.

$\mathrm{Na}$ abordagem hermenêutica, destacam-se os estudos de Santos e Cardoso (2016) na busca de experiências vividas, através de estudo de caso e com revisão de literatura, os quais realizaram interpretações das experiências dos docentes em uma universidade portuguesa; Hardy et al. (2016) analisou a parentalidade na Austrália, através de grupo focal, com 41 homens, evidenciando-se as experiências docentes com inferências dos autores; Fotbergil e Felltey (2004) trataram sobre mães com filhos e a carreira acadêmica, por entrevistas e analisaram as experiências em uma universidade dos EUA; Hirakata e Daniluk (2009), por um estudo de caso com entrevistas aprofundadas, sem utilização de teorias como base, utilizaramse métodos de análise fenomenológica propostos por Colaizzi (1978) e Mishler (1986), com interpretações dos resultados; Doherty e Manfredi (2006), por meio de um modelo de pesquisa-ação sobre equilíbrio trabalho família, através de análise conteúdo, comparou as políticas e práticas do equilíbrio trabalho família na universidade do Reino Unido; Rafnsdóttir e Heijstra (2011) analisaram as experiências docentes na Islândia investigaram WFC e o fator de gênero, com inferências; Wendel e Ward (2006), estudaram o WFC em tipos diferentes de universidades nos Estados Unidos, através da abordagem comparativa constante; e Armenti

Perspectivas em Gestão \& Conhecimento, João Pessoa, v. 11, n.1, p. 118-143, jan./abr. 2021. 
(2004), realizou um estudo de caso com mães com filhos e carreira acadêmica em Universidade no Canadá. Destacam-se estudos voltados para maternidade e carreira acadêmica de mulheres, em que nos aponta uma maior vulnerabilidade entre os sexos.

Destaca-se nos estudos positivistas (30\%) a busca da explicação dos fatos a partir de suas relações. $O$ estudo dos fenômenos são desvinculados de uma dinâmica ampla, utilizandose de uma teoria como base e escalas de atitude nos questionários. Assim, enquadraram-se nesses critérios os artigos de Bianchim et al. (2019), que utilizaram a teoria do entrincheiramento com base e o emprego de escalas de atitudes validadas por Bastos e Aguiar (2014), restrita às Universidades de Santa Maria, no Estado do Rio Grande do Sul (RS); Moreira e Silva (2018), que utilizaram a teoria dos papeis para dar suporte as argumentações e através de 4 escalas de atitude estudaram o gênero feminino das universidades do RS relacionadas ao WFC; Carvalho et al. (2018) utilizaram a bidirecionalidade como base e a escala TF de Carvalho e Andrade (2012), com 92 itens, apresentando seus resultados através de modelação de equações estruturais, estudo restrito a uma universidade portuguesa; Takahashi et al. (2012) analisaram os docentes intraempreendedores, por meio de uma análise documental e entrevistas e, apesar de não utilizar escalas, as entrevistas se basearam na teoria dos papeis, restringindo-se a Universidade Federal do Paraná; Afrianty, Burgess e Issa (2016) utilizaram como base a Teoria da conservação dos recursos, com uso de correlação estatística, e escala de Allen (2001); Noor (2011) utilizou da teoria dos papeis como base, tendo sua escala de atitude validada em estudo no ensino superior da Malásia, utilizando a correlação e análise de mediação. Assim, destaca-se a utilização de escalas de atitude e opinião já validadas e pesquisas survey com utilização de questionários nos estudos positivistas sobre o WFC.

Por sua vez, a abordagem fenomenológica descritiva, que obteve $20 \%$ nos artigos analisados, também busca constatar as experiências dos participantes e dos autores, e realizam-se por meio de entrevistas, principalmente com mulheres, distinguindo-se da hermenêutica, pois nessa abordagem não se realizam interpretações dos resultados e inferências dos autores. Destacaram-se os estudos de Takahashi et al. (2014), pesquisa de comparação do WFC, em três universidades do Paraná, por meio do modelo multidimensional para verificar o fator gênero, em um estudo de caso por meio de entrevistas; Reddick, Rochlen e Grasso (2012), pesquisa com chefes de departamentos de uma Universidade nos EUA, por meio entrevistas aprofundadas sobre parentalidade; Quevedo, Fleck e Carmo (2013) através de uma pesquisa qualitativa através de entrevistas para verificar o equilíbrio Trabalho Família com docentes em uma universidade; O'meara e Campbel (2011) sobre decisões de carreira relacionadas o WFC passou a descrever as experiências dos docentes diante das decisões tomadas e analisou os dados pelo método comparativo constante de Merriam (1998).

A abordagem empírica apresentou dois estudos, que representam $10 \%$ da amostra, onde se buscaram superar a subjetividade e o juízo de valor e não reconheceram a utilização de teorias para amparar suas investigações. Tais pesquisas se processaram através de experimentos e identificaram-se em Fox (2005), pesquisa survey com questionário para evidenciar questões de gênero, casamento, e produção cientifica; Fox, Fonseca e Bao (2011), os quais utilizaram pesquisa survey com questionário, regressão logística e não utilizaram escalas validadas, sendo a pesquisa realizada em 9 universidades dos EUA. Assim, destaca-se nesse tipo de abordagem a não utilização de uma teoria como base da pesquisa.

\subsection{Polo técnico}

O estabelecimento do polo técnico se evidencia pelos procedimentos de coleta de dados e sua compilação para transformarem em informações que se procuram para alcançar os objetivos desse estudo. As escolhas do polo técnico estão relacionadas aos pesquisadores,

Perspectivas em Gestão \& Conhecimento, João Pessoa, v. 11, n.1, p. 118-143, jan./abr. 2021. 
que são os meios plausíveis e recomendados para se realizar as pesquisas (THEÓPHILO; IUDíCIBUS, 2005). A análise desse polo resume-se na Tabela 4.

$\mathrm{Na}$ análise do polo técnico, em que se estabelecem as estratégias utilizadas nos estudos, constataram-se que as preferências dos pesquisadores foram natureza qualitativa (60\%); como tipo de estratégia, o estudo de caso (50\%); a técnica de coleta de dados, a entrevista com 45\%; o público predominante foi docentes de ambos os gêneros (50\%), evidenciando ainda que na ótica dos pesquisadores sobre o WFC, o país com o maior número de estudos foram os Estados Unidos com 50\%.

Tabela 4 - Estratégias técnicas da produção cientifica sobre WFC com docentes

\begin{tabular}{cccccc}
\hline Natureza & $\mathbf{F i}$ & $\%$ & Participantes & $\mathbf{F i}$ & $\mathbf{\%}$ \\
\hline Qualitativa & 12 & $60 \%$ & Homem e Mulher & 10 & $50 \%$ \\
Quantitativa & 7 & $35 \%$ & Mulher & 7 & $35 \%$ \\
Qualitativa-Quantitativa & 1 & $5 \%$ & Homem & 3 & $15 \%$ \\
\hline Estratégia de pesquisa & $\mathbf{F i}$ & $\%$ & Técnica de Coleta de Dados & $\mathbf{F i}$ & $\%$ \\
\hline Estudo de caso & 10 & $50 \%$ & Entrevista & 9 & $45 \%$ \\
Survey & 7 & $35 \%$ & Questionário & 7 & $35 \%$ \\
Revisão de Literatura & 2 & $10 \%$ & Questionário e Entrevista & 2 & $10 \%$ \\
Documental & 1 & $5 \%$ & Pesquisa documental & 1 & $5 \%$ \\
& & & Grupo focal & 1 & $5 \%$ \\
\hline
\end{tabular}

Fonte: Elaborada pelos autores (2020).

A representatividade de $55 \%$ dos estudos de natureza qualitativa, relaciona-se com a abordagem predominante fenomenológica, instrumento que se utilizou na verificação das experiências dos entrevistados; o estudo de caso (50\%) foi a estratégia de pesquisa escolhida, como técnica de coleta de dados; as entrevistas (45\%) com aprofundamento de análise de conteúdo, com um número reduzido de participantes, e observou-se que esses estudos na sua maioria não se baseavam em uma teoria específica para realizar as análises, mas sim, através de um arcabouço teórico por meio de um profundo referencial teórico, correlacionaram-se com predominância nessa configuração, os estudos fenomenológicos hermenêuticos e descritivos.

Por sua vez, as pesquisas de natureza quantitativa (35\%) estão em conformidade com a segunda abordagem metodológica, a positivista, em que as variáveis são exploradas, através de estratégia survey (35\%) e tem como técnica de coleta de dados, o questionário (35\%), elaborados em escala de likert. Destaca-se que os estudos quantitativos utilizaram escalas validadas, tendo como principais as de Greenhaus e Beutel (1985), Carson e Bedeian (1994) e Allen (2001). Nesses tipos de estudos, destacam-se as ferramentas estatísticas, tais como Biachim et al. (2019) com análise de regressão linear múltipla; Moreira e Silva (2018) através da correlação de Pearson e regressão linear múltipla; Carvalho et al. (2018) com o uso da análise fatorial e modelagem estrutural; Afrianty, Burgess e Issa (2016) por meio da correlação; Fox, Fonseca e Bao (2011), que utilizaram a correlação, fatorial e regressão logística; Noor (2011) usaram a correlação e análise de mediação; e Fox (2005) a correlação. Nesses estudos, buscou-se a objetividade na apresentação dos dados coletados.

Apresentaram-se ainda, estudos de natureza qualitativa-quantitativa (5\%), com estratégias survey e estudo de caso. Biachim et al. (2019) utilizou estudos qualitativos, com revisão de literatura (10\%), com estudos de Santos e Cardoso (2016) e Hardy et al. (2018) pesquisa documental (5\%), tomando-se como base a pesquisa de Takahashi et al. (2012).

Constata-se no polo técnico a preferência por estudos qualitativos, em que se observa a preocupação dos autores em não utilizar modelos já estabelecidos para promover suas pesquisas, conforme Noor (2011) e Hardy et al. (2018), em que tal fato se destaca, em especial, por discordâncias culturais, sociais e econômicas, que fazem com que se prefira

Perspectivas em Gestão \& Conhecimento, João Pessoa, v. 11, n.1, p. 118-143, jan./abr. 2021. 
estudar o WFC através de subjetividades, por entenderem que, dessa forma, as pesquisas estariam menos comprometidas com vieses dos países e das universidades.

\subsection{Discussões dos estudos}

Após realizar a análise sistemática pelos quatro polos, passou-se a analisar a discussão dos pontos principais das pesquisas evidenciadas pelos autores nesse estudo, em que se dividiu em: parentalidade, carreira acadêmica, percepção de gênero, políticas e apresentação das lacunas observadas sobre WFC.

\subsubsection{Parentalidade e o WFC}

A parentalidade é o estado ou condição de quem se assume como pai ou mãe de uma criança. Sobre o Word-Family Conflict (WFC) com docentes de nível superior (Hard et al., 2016), passa-se a discorrer sobre maternidade e paternidade de docentes com filhos na vida acadêmica. Dentre os artigos que podem resumir o contexto dessa dimensão, destacam-se o de Fotbergil e Felltey (2004), com o título: "eu trabalhei muito duro e dormi muito pouco, mães na faixa de posse na academia" e o de Armenti (2004) "o gênero como uma barreira para mulheres com filhos na academia".

O WFC entre acadêmicos é uma questão relevante na gestão do ensino superior. Para acadêmicos que são pais, os compromissos familiares podem aumentar a pressão do WFC, com o aumento da carga de trabalho. Um corpo robusto de literatura trata dos desafios de equilíbrio da carreira acadêmica com a parentalidade. Resultados de pesquisas evidenciam que - WFC se observa mais significativo para as mulheres, em que se destacam as variáveis sexismos, feminismo, tempo de posse e percepção de gênero, evidenciadas nas pesquisas de Armenti (2004), Wolfinger, Mason e Golden (2008), Hirakata e Daniluk (2009); Reddick et al. (2012) e Hard et al. (2016). Ressalte-se ainda que o desafio das mulheres é ainda maior, dada as demandas físicas da maternidade, expectativa de gênero nas obrigações familiares e assunção do 'segundo turno' por meio do amparo das crianças e do lar (WENDEL; WARD, 2006).

No estudo realizado por Fothergill e Feltey (2004), os autores destacaram que as mães não conseguem obter êxito no duplo papel (trabalho-família), e que isso esclarece o estereótipo sobre mulheres mães, que prevalece em muitos contextos. Corrobora nesse sentido Armenti (2004), destacando que mulheres que querem ter filhos devem analisar esta decisão cuidadosamente, principalmente no início de carreira. Uma interpretação dessa pesquisa, pelo feminismo cultural, destaca que as mulheres são toleradas e não aceitas na academia, apontando a necessidade de reestruturação das carreiras acadêmicas para acomodar mulheres com crianças na profissão (HOWE-WALSH; TURNBULL, 2014).

Na pesquisa de Reddick et al. (2012), em estudos realizados com pais na academia, os autores destacaram que realizam as tarefas domésticas e cuidado com os filhos menores, mas reconhecem a desvantagem das mulheres, principalmente pelos aspectos biológicos que mantém as mulheres no lar, como, reabilitação do parto e amamentação, e sugerem como estratégia de enfrentamento do WFC a obtenção de um planejamento efetivo do uso do tempo e manter uma boa comunicação com o cônjuge e colegas de trabalho para superarem as responsabilidades profissionais e familiares.

Em pesquisa realizada por Wendel e Ward (2006), os pesquisadores contribuem para os estudos sobre WFC, sinalizando que o tipo institucional faz a diferença para professoras na faixa de posse que pretendem ter filhos, onde o campus em que se trabalha molda o trabalho acadêmico, destacando-se que universidades de pesquisa não seriam ideais para mães, enquanto, faculdades de artes liberais e comunitárias apresentam um maior equilíbrio sobre o

Perspectivas em Gestão \& Conhecimento, João Pessoa, v. 11, n.1, p. 118-143, jan./abr. 2021. 
WFC. Entretanto, há evidências na literatura, ao sugerir que mães que desejam a maternidade são incentivadas a fazê-lo em instituições de nível inferior, pois tais achados contrariam a pesquisa de Fox (2005), que evidenciou em programas de doutorado nos EUA que a produção de mulheres com filhos foi maior, por serem um grupo focado e seletivo nos seus objetivos e relataram que a convivência em um departamento pouco competitivo e estressante aumenta o WFC.

Sobre a diversidade de abordagens do WFC, Hard et al. (2016) reconhecem a heterogeneidade das situações na carreira acadêmica, citando como exemplo a paralisação da carreira parking para cuidar dos filhos, utilizada como estratégia de enfrentamento, mas constatou-se que essa ação promove um elevado ressentimento emocional. Por isso, estudos realizados por O'meara e Campbell (2011) e Hirakata e Daniluk (2009) destacaram a relevância do apoio institucional, especialmente de orientadores de apoio às famílias, desempenhando um papel essencial, aumentando a satisfação no trabalho e reduzindo as intenções de deixar o emprego.

O senso de vulnerabilidade das mães sobre WFC foi destacado por Hirakata e Daniluk (2009), em que mães foram sugestionadas a não tirarem licença maternidade para não prejudicarem sua carreira, e voltaram a trabalhar logo após o parto, e ainda se destacou o senso de isolamento, que as mulheres com filhos sofrem dos colegas, pois os mesmos as veem como não comprometidas com o trabalho. Willians (2004) refere-se ao fenômeno da 'parede materna', que refletem padrões institucionalizados de estereótipos que impactam as mães em relação às mulheres em geral. Nesse mesmo entendimento, Fothergill e Feltey (2004) destacaram que a licença maternidade é classificada de 'licença por doença' ou 'incapacidade de curto prazo', declarando que a academia não foi projetada para mulheres.

\subsubsection{Carreira acadêmica e o WFC}

Um dos fatores constatados nos estudos sobre carreira e WFC, referem-se ao estágio de posse. As docentes com filhos, nessa fase, passam por sérias dificuldades com a maternidade, fato esse, não observado com as titulares e associadas. Hirakata e Daniluk (2009) e Armenti (2004), em suas pesquisas, refletiram sobre as docentes, as quais não conseguiram atender às diligências de trabalho e família; Hard et al. (2016) sugere a existência de um viés institucional para as mulheres obterem a posse, em que, a carreira típica exige um período para superação dessa fase, seis anos na América do Norte e três anos na Austrália, e esse período muitas vezes coincide com o pico dos anos férteis das mulheres. Fothergill e Feltey (2004), observaram que as políticas de controle de posse precisam ser modificadas e flexibilizadas para que as mulheres possam ter filhos.

Acerca das apreensões com a redução da produtividade acadêmica, que acompanha a parentalidade, mais incisiva sobre a mulher, principalmente por aspectos biológicos, Quevedo, Fleck e Carmo (2013), observam que essas exigências promovem o não atendimento das necessidades familiares. Pesquisas sugerem que a utilização de benefícios de licença familiar pode promover uma melhor experiência de vida familiar e impulsionar a produtividade (HARD et al., 2016; REDDICK et al., 2012). Embora a maioria das mulheres descreveu uma carreira menos produtiva por terem filhos, isso não significa que elas eram improdutivas (base em medidas como a publicação), pelo contrário estavam comprometidas com seus alunos, ensinando, desenvolvendo projetos e pesquisando (FOTHERGILL; FELTEY, 2004; HIRATA; DANILUK, 2009; HARD et al., 2016).

A questão da baixa produtividade para as mães com filhos também foi evidenciada por Reddick et al. (2012) e ainda, a preocupação com a percepção dos colegas, em que se sentiam mais valorizadas antes da gestação. Destacaram ainda que as restrições de tempo e suas responsabilidades parentais exigiram que se tornassem mais eficientes; mas apesar desse

Perspectivas em Gestão \& Conhecimento, João Pessoa, v. 11, n.1, p. 118-143, jan./abr. 2021. 
cenário de dificuldades, apresentou-se um paradoxo: se por um lado, o ambiente acadêmico se mostrou estressante e exigente, ao mesmo tempo, por outro, oferece flexibilidade e autonomia, característica positiva para amenizar o WFC (MOREIRA, 2018; FOTHERGILL; FELTEY, 2004; O'MEARA; CAMPBELL, 2011; HARD et al., 2016).

O sucesso profissional na docência foi destacado por Moreira e Silva (2018). No referido estudo, as docentes o associaram ao comprometimento com a carreira, destacando que quanto maior o nível de identidade à profissão, maior será o nível de resiliência e, consequentemente, de êxito profissional. Evidencia-se ainda que essa instituição apresentou ambiente saudável e horários flexíveis, ressaltando-se que esse estudo não obteve resultados negativos nas dimensões trabalho e família. Nas pesquisas de Bandeira, Ferreira e Cabral (2020), Vilela et al. (2018), Vilela e Lourenço (2017), Feijó et al. (2017), Vilela (2018), Braun, Vierheller e Oliveira (2016), os arranjos de trabalhos flexíveis também foram apontados como o principal mecanismo para amenizar os impactos do WFC.

Em pesquisa realizada por Afrianty, Burgess e Issa (2016), com análise realizada no ensino superior da Indonésia, foi constatada elevada carga de trabalho e baixa percepção do conflito. Nas sociedades orientais, o trabalho extra pode ser legitimado ou até incentivado e seja um auto sacrifício feito para a família, onde os acordos de flexibilidade de horários podem significar perda de renda e aumento do WFC, não se alinhando com as práticas ocidentais. Ressalta-se ainda que as questões culturais dos países sobre WFC devem ser observadas na promoção de políticas para amenizar o WFC. Nesta perspectiva, Noor (2011) corroborou, evidenciando a relevância da observância dos aspectos culturais no estabelecimento de políticas para o WFC.

Por sua vez, Biachim et al. (2019) desenvolveram estudo para comparar o nível de percepção do conflito TF, em IES públicas e privadas e observaram que os docentes das IES públicas apresentaram níveis elevados do WFC, enquanto as IES privadas, nível médio. Justificam-se que os primeiros estariam envolvidos em ensino, pesquisa e extensão, possuindo uma agenda cheia; os horários flexíveis utilizados pelas IES públicas não se evidenciam nas IES privadas, por terem regras diferentes. Os resultados permitem concluir que, de forma geral, a instituição de ensino em que atuam é um fator relevante para as regras de convivência, corroborando com o estudo de Wendel e Ward (2006), sobre a necessidade de avaliar a instituição que se pretende trabalhar.

Destacam-se ainda, temas que a docência superior foi pesquisada através do WFC. As competências empreendedoras e o WFC, foram analisadas por Takahashi et al. (2012), em que, constataram que as mesmas promovem o aumento do conflito nos papeis trabalho e família. Em outra temática estudada sobre o WFC, Quevedo, Fleck e Carmo (2013) pesquisaram sobre dedicação exclusiva e tempo para a família, evidenciando que os docentes mantêm a gestão do tempo de trabalho e do tempo livre, mas que a atividade docente interfere na vida pessoal, a ponto de influenciar significativamente às suas vidas.

Por fim, destacam-se mecanismos que forma utilizados para amenizar o WFC. Reddick, Rochlen e Grasso (2012) e Takahashi et al. (2012), evidenciaram recusar trabalhos adicionais, como aulas em outras instituições, evitar viagens de negócios ou participação em muitos eventos, aproveitar as oportunidades e viajar com a família, inserir esposas e filhos em atividades de ensino, tentar não levar muitos trabalhos para casa, assim como, práticas de lazer para aliviar o estresse diário, música e leitura não técnica; Fox, Fonseca e Bao (2011) destacam a implantação de programas extracurriculares e programas de acolhimento às crianças, para atenuar o conflito. Contribuíram ainda, Quevedo, Fleck e Carmo (2013) sugerindo o planejamento das tarefas, com estabelecimento de prioridades, e o foco de trabalho em uma única atividade (dedicação exclusiva) são fatores que podem atenuar o WFC.

Perspectivas em Gestão \& Conhecimento, João Pessoa, v. 11, n.1, p. 118-143, jan./abr. 2021. 


\subsubsection{Percepção de Gênero e o WFC}

Nos artigos analisados, quatro destacaram-se como objeto de estudo sobre gênero, os docentes definiram sua carga de trabalho, como dura, com elevadas demandas de cunho administrativo, realização de tarefas na residência e a conciliação de ensino e pesquisa, evidenciaram como um dos principais fatores influenciadores do WFC (TAKAHASHI et al., 2014; RAFNSDÓTTIR; HEIJSTRA, 2011). Evidenciaram que a mulher é a mais impactada pela tríplice jornada (trabalho, família, estudos); da mesma maneira, Carvalho et al. (2018) que investigou a invariância entre sexos, em docentes do ensino superior de Portugal, constataram que a bidirecionalidade do conflito (trabalho-família e família trabalho), variam entre os sexos, apresentando uma maior carga para as mulheres. Takahashi et al. (2014), por sua vez, observaram que o efeito do WFC em menor grau sobre os homens, corroborando Rafnsdóttir e Heijstra (2011), que isso se dá pelo fato dos homens gerenciarem melhor o tempo de que as mulheres. Em estudos anteriores relacionados a gênero sobre o WFC, os mesmos identificaram a mulher como a mais impactada pelo conflito (BANDEIRA; FERREIRA; CABRAL, 2020; VIELA, et al., 2018; FEIJÓ et al., 2017; VILELA; LOURENÇO, 2017; BRAUN; VIERHELLER; OLIVEIRA, 2016).

Em pesquisa realizada por Fox (2005) sobre gênero, relatou-se que a relação entre casamento e produtividade varia de acordo com o tipo de casamento. Mulheres em casamentos subsequentes têm maior produtividade do que as mulheres em primeiros casamentos. Os efeitos seriam positivos na produção cientifica, isto é, ser casado com pessoas da mesma área científica ameniza o conflito; a produção de mulheres com filhos é maior que as mulheres sem filhos, esses dados mostram que casamento e crianças pequenas não estão relacionados à produtividade frustrada da publicação entre as mulheres na academia.

Em pesquisa realizada na Islândia, por Rafnsdóttir e Heijstra (2011), os acadêmicos desfrutam de flexibilidade no trabalho, que seria a vantagem de ser docente, embora, a flexibilidade ajude os pais a organizar seu trabalho-família, as mulheres, parecem estar presas às responsabilidades domésticas e acabam sendo as mais impactadas; mesmo assim, a flexibilidade nos horários e o teletrabalho, ajudam a melhorar o equilíbrio entre TF.

Como meios para amenizar o WFC, destacaram-se Takahashi et al. (2014) os quais apontaram a necessidade de implantação de políticas para a parentalidade, tanto no público, como no privado e a flexibilização de horários foram relacionadas por Carvalho et al. (2018), Takahashi et al. (2014), Rafnsdóttir e Heijstra (2011) e Fox (2005), como o principal veículo amenizar o WFC. Embora o horário de trabalho flexível ajude os pais acadêmicos a organizar seu dia de trabalho e atender às necessidades da família, as mulheres, parecem estar presas às questões domésticas, por causa dessa mesma flexibilidade, o uso do tempo por gênero parecem assim reproduzir as relações tradicionais de poder entre mulheres e homens e a divisão segregada por gênero nos lares (RAFNSDÓTTIR; HEIJSTRA 2011).

\subsubsection{Políticas para amenizar o WFC}

Em estudos sobre políticas para amenizar o WFC, Doherty e Manfredi (2006) evidenciaram a progressão na carreira docente, através das políticas de equilíbrio TF em um contexto universitário, onde procuraram pelo gerenciamento da carga de trabalho, por ser uma prática cultural no Reino Unido, dificultando o equilíbrio entre TF, como políticas que se evidenciaram para a redução do WFC destacaram-se, melhora na comunicação e divulgação das políticas existentes, revisar as políticas com sindicatos, promoção de workshops para integrar grupos e compartilhamento das melhores práticas, foram as sugestões apresentadas.

Na pesquisa de O'meara e Campbel (2011) discutiu-se sobre as políticas existentes no contexto acadêmico sobre TF, constatando-se que existem fatores que podem influenciar o WFT que estão fora do controle, como, gênero, parceiro de apoio, flexibilidade no trabalho do

Perspectivas em Gestão \& Conhecimento, João Pessoa, v. 11, n.1, p. 118-143, jan./abr. 2021. 
parceiro, número de filhos, observaram sobre trabalhar o preconceito contra a prestação de cuidados infantis e apoiar o utilização de políticas já existentes para os professores e incentivar o uso das políticas para todos os gêneros. Essas mesmas dificuldades evidenciadas para implantação de políticas para amenizar o CTF, foram identificadas nos estudos de Vilela e Lourenço (2017), em que, evidenciaram que políticas organizacionais e governamentais não conseguem a sua efetivação e Feijó et al. (2017), acrescentam que as mesmas só serão efetivas com a aceitação e colaboração dos gestores.

Na última pesquisa sobre políticas WFC encontrada, Santos e Cardoso (2016), os dados também evidenciaram que as políticas para amenizar o WFT são infrutíferas, a menos que sejam apoiadas pelas instituições. Na análise, surgiram agravantes do WFC, como divisão desigual de tarefas domésticas e de assistência a infância, constatou-se a falta de contribuição da universidade relacionada à paternidade e à creche; e as pressões das atividades familiares são acomodadas em redes de assistência mútua envolvendo vizinhos e familiares ou adquirindo serviços domésticos. (SANTOS; CARDOSO, 2016; O'MEARA; CAMPBEL, 2011; DOHERTY; MANFREDI, 2006). Essas mesmas dificuldades evidenciadas para implantação de políticas para amenizar o WFC, foram identificadas nos estudos de Vilela e Lourenço (2017), onde destacaram que políticas organizacionais e governamentais não conseguem a sua efetivação e Feijó et al. (2017), acrescentam que as mesmas só serão efetivas com a aceitação e colaboração dos gestores.

As constatações que se destacaram nos estudos entre os países das pesquisas, em estudo de Dorothy e Manfredi (2006) no Reino Unido, a prática cultural dos docentes que para obterem êxito nas carreiras precisam de horas excessivas de labor, sendo um agravante para o WFC. Por sua vez, em estudo realizado na Indonésia por Afrianty, Burgess e Issa (2016), por questões culturais asiáticas, e pela baixa faixa de renda da população, o WFC, é pouco percebido, pela cultura dos trabalhos extras serem legitimados ou até incentivados nessa sociedade e em outro estudo na Indonésia de Noor (2011), acrescenta que as instituições de ensino superior, com a abertura do mercado global estão aderindo aos princípios orientadores da ordem econômica e passando a adotar horários flexíveis de trabalho.

\subsubsection{Lacunas de pesquisas sobre o WFC}

A análise dos objetivos e dos artigos proporciona a identificação de possibilidades de pesquisas futuras, tais como: (i) Bianchi et al. (2019) sugerem que seja investigada a relação entre as políticas de apoio ofertadas pelas instituições de ensino, o conhecimento que os profissionais possuem sobre elas e seus efeitos sobre as interfaces entre TF; (ii) Moreira e Silva (2018) sugerem a realização de estudos objetivando diferenciar as associações das mulheres casadas para com as mulheres solteiras, e a percepção entre homens e mulheres; (iii) Santos e Cardoso (2016) destacam a necessidade de estudos para promover uma análise do 'porquê' as universidades não acompanham as transformações sociais e culturais nos arranjos de TF que se promovem em outros tipos de organizações; (iv)Takahashi et al. (2014) recomendam o desenvolvimento de pesquisas com professores de outros níveis de ensino, para avaliar como se processa o WFC; (v) Afrianty, Burgess e Issa (2016) sugerem analisar como as questões culturais de diferentes países abordam e tratam o WFC; (vi) O'meara e Campbel (2011) recomendam analisar quem deve ser o tutor dos professores iniciantes que enfrentam problemas WFC, através da cultural organizacional das universidades; e (vii) Armenti (2004) propõe que seja pesquisado se o viés de gênero nas universidades é um problema sistêmico ou um estigma cultural relacionado ao WFC. 


\section{CONSIDERAÇÕES FINAIS}

Tendo em vista os aspectos observados na revisão sistemática sobe o WFC na docência do ensino superior, em que se vislumbrou o professor universitário como um profissional assoberbado nas suas demandas profissionais para atender ensino, pesquisa e extensão, essas três dimensões se desdobrando em outras variáveis, o elegendo com um ator a ser afligido pelo WFC, principalmente pela alta carga de trabalho, o estudo propôs como objetivo analisar como se caracterizam as pesquisas que tratam do conflito trabalho-família relacionadas aos docentes de nível superior em periódicos nacionais e internacionais, em que se utilizou da categorização de Theóphilo e ludícibus (2005), que propuseram quatro polos para se promover uma análise sistemática: epistemológico, teórico, metodológico e técnico, para realizar estudos dessa natureza.

Com os resultados, constatou-se que, no polo epistemológico, foram analisados os objetivos, destacando-se os compreensivos (30\%) e avaliativos (30\%). No polo teórico, foram analisadas as abordagens teóricas, com destaque para a teorização do WFC, proposta por Greenhaus e Beutell (1985), representando 55\% das pesquisas e ainda, evidenciaram-se as temáticas apresentadas, onde a maternidade na docência (30\%) e percepção entre gênero (20\%) foram as que mais se destacaram, evidenciando a falta de apoio institucional para as mães e que, na questão de gênero, a mulher é a mais impactada pelo conflito.

No polo metodológico, evidenciaram-se pesquisas fenomenológicas hermenêutica (40\%), com utilização de entrevistas aprofundadas, com análise de conteúdo e interpretação dos resultados; e positivista (30\%), que através de métodos científicos, pesquisa survey e com coleta de dados por questionário com escalas de atitude validadas, apresentaram, no geral, uma teoria como base para as argumentações. Por sua vez, no polo técnico, constatou-se quanto a natureza da pesquisa as qualitativas (55\%); quanto às estratégias, o estudo de caso $(50 \%)$ e as entrevistas (45\%) como a técnica de coleta de dados. Ressalte-se ainda que os países com o maior número de estudos foram os EUA (50\%).

A predominância dos estudos sobre WFC analisados, são de pesquisa fenomenológica, com utilização de entrevistas aprofundas, com análise de conteúdo, em que não se utilizam de uma teoria como base. Em relação a essa configuração, divergem das pesquisas anteriores de Bandeira, Ferreira e Cabral, (2020), Feijó et al. (2017), Braun, Vierheller e Oliveira (2016), em que se evidenciaram estudos quantitativos, pesquisa survey, através de questionários validados, utilizando-se uma teoria como base para analisar os dados.

Sobre a Maternidade e o CTF, destacou-se a predominância das mães serem mais vulneráveis ao conflito, por não haver uma divisão justa das tarefas domésticas, pela tríplice tarefa (trabalho-família-estudos), discriminação das mães, vistas como não comprometidas com a academia, gerando frustação e até intenção de abandonar a carreira, e as universidades de pesquisas apresentaram-se como as de maior agravante com o conflito em estudo.

Com relação aos estudos sobre gênero, constatou-se as desigualdades entre os sexos, destacando o ambiente laboral desfavorável para o feminino, alinhando-se aos achados de Vilela et al. (2018), Vilela e Lourenço (2017) e Feijó et al. (2017). Nos estudos relacionados sobre políticas públicas ou institucionais para amenizar o CTF, constatou-se que as políticas só podem ser exitosas com o apoio das instituições, em que decisões sobre o Trabalho-Família, nas pesquisas de Feijó et al. (2017), Vilela e Lourenço (2018) corroboram com essa assertiva, mas, esse último, complementa que as políticas não são efetivadas por inibição dos funcionários, que julgam que ao utilizá-las prejudicaram suas carreiras.

Quando aos aspectos relacionados a carreira, destacaram-se pressões para atender os rankings de pesquisas, processo identificado em várias universidades. Como observações para amenizar o WFC, evidenciaram-se recusa de trabalhos adicionais em outras universidades e redução de participação de eventos. Nos estudos sobre a questão de gênero sobre o WFC,

Perspectivas em Gestão \& Conhecimento, João Pessoa, v. 11, n.1, p. 118-143, jan./abr. 2021. 
destacaram-se as mulheres como as mais impactadas, evidenciando que os efeitos em menor grau sobre os homens, destacaram-se como fontes geradoras do conflito: demandas administrativas, produção científica e preconceito com as mulheres por serem mães, apontando-se como principais formas de amenizar o CTF a implantação de políticas para a parentalidade, em todas as esferas e a flexibilização de horários, sendo citados nas pesquisas de Bandeira, Ferreira e Cabral (2020), Vilela et al. (2018), Feijó et al. (2017), Vilela e Lourenço (2017) e Braun, Vierheller e Oliveira (2016), como o meio mais citado para se amenizar o WFC.

Dessa forma, entende-se que o objetivo foi atingido, tendo em vista que foi possível analisar a trajetória da produção científica nacional e internacional acerca do tema a partir de múltiplas perspectivas (polos, epistemológico, teórico, metodológico e técnico). Destarte, esse estudo contribui na evidenciação de como estão sendo desenvolvidas as pesquisas relacionadas com o WFC, destacadamente pesquisas fenomenológicas, na busca das experiências dos participantes através de entrevistas aprofundadas, e com análise dos resultados pelos pesquisados, essas evidenciações podem direcionar os estudiosos sobre como desenvolver pesquisa para academia, pois evidenciam-se aspectos relevantes relacionados ao WFC na docência superior e ações para amenizá-los. Ademais, traz orientações pertinentes acerca do WFC na docência superior, ao constatar a carência de políticas próprias para cada país e a reestruturação das carreiras docentes para atender as mães docentes, que são as mais vulneráveis para este conflito.

O estudo avança nos campos teórico e social, entretanto algumas limitações podem ser apontadas, razão pela qual se sugere para futuras pesquisas, que sejam realizados estudos sobre o WFC considerando as especificidades dos países onde estão sendo realizados, observando os aspectos culturais, de gênero, sociais, demográficos, pois, constatou-se que essas variáveis interferem no modo como o WFC é visto e como é tratado.

\section{REFERÊNCIAS}

AFRIANTY, W.; BURGESS, J.; ISSA, T. Family-friendly support programs and work family conflict among Indonesian higher education employees, Equality, Diversity and Inclusion: an International Journal, v. 34, n. 8 p. 726-741, 2015. https://dx.doi.org/10.1108/EDI-04-2015$\underline{0026}$

ALLEN, T. D. Family supportive work environments: the role of organizational perceptions, Journal of Vocational Behavior, v. 58, n. 3, p. 414-435, 2001. http://doi:10.1006/jvbe.2000.1774

ARMENTI, C. Women Faculty Seeking Tenure and Parenthood: Lessons from Previous Generations. Cambridge Journal of Education 34, n.1, p. 65-83. 2004. Disponível em: file:///C:/Users/slpsc/Music/FWA/artigos/37\%20Armenti\%202004.pdf Acesso em: 8 jun. 2020.

ANDRADE, A. L de.; OLIVEIRA, M. Z de.; HATFIEL, E. Conflito trabalho-família: Um estudo com brasileiros e norte-americanos. Revista Psicologia: Organizações e Trabalho, Vitória, abr/jun, v. 17, n. 2, p.106-113, 2017. http://dx.doi.org/10.17652/rpot/2020.2.17382

BANDEIRA, E. L.; FERREIRA, V. C.; CABRAL, A. C. de A. Conflito trabalho-família: a produção científica internacional e a agenda de pesquisa nacional. REAd, Porto Alegre, v. 25, n.1, Jan/abr., p. 49-82, 2020. http://dx.doi.org/10.1590/1413-2311.232.87660

Perspectivas em Gestão \& Conhecimento, João Pessoa, v. 11, n.1, p. 118-143, jan./abr. 2021. 
BASTOS, A. V.; AGUIAR, C. V. N. Conflito trabalho-família. SIQUEIRA, M. M. M. (Coord.). Novas medidas do comportamento organizacional: Ferramentas de diagnóstico e de gestão. Porto Alegre: Artmed, 2014.

BEUREN, I. M. (Organizador). Como elaborar trabalhos monográficos em contabilidade: teoria e prática. São Paulo: Atlas, 2006.

BIANCHIM, B. de V.; POSSER, T. G.; COSTA, V. M. F.; ALMEIDA, D. M de. Trabalho e Família: o docente frente ao conflito da interface positiva. In: COLÓQUIO INTERNACIONAL DE GESTÃO UNIVERSITÁRIA, $19 ., \quad 2019 . \quad$ Disponível em: https://repositorio.ufsc.br/handle/123456789/200759 acesso em: 14 mai 2020.

BRAUN, A. C.; VIERHELLER, B.; OLIVEIRA, M. Z. de. Conflito trabalho-família em executivos: uma revisão sistemática de 2009 a 2014. Revista Brasileira de Orientação Profissional jan/jun., v. 17, n. 1, p.19-30, 2016. Disponível em: Disponível em https://pepsic.bvsalud.org/scielo.php?script=sci issues\&pid=1679-3390\&lng=pt\&nrm=iso Acesso em: 07/06/2020.

CARLOTO, M. S.; CÂMARA, S. G. Tradução, adaptação e exploração de propriedades psicométricas da Escala Interação Trabalho-Família Nijmen (SWING) em uma amostra de professores brasileiros. Estudos de Psicologia, n.19, v.3, p. 157-238, jul/set, 2014. https://doi.org/10.1590/S1413-294X2014000300006

CARLSON, D. S.; KACMAR, K. M.; WILLIAMS, L. J. Construction and initial validation of a multidimensional measure of work-family conflict. Journal of Vocational Behavior, n56, v.2, p. 249-76, 2000. https://doi:10.1006/ivbe.1999.1713

CARSON, K. D.; BEDEIAN. Career Commiment: construvtion of a measure and examination of its psychometric properties jornal of vocation behavior, n. 44, p. 237-262, 1994. https://doi.org/10.1006/jvbe.1994.1017

CARVALHO, C. S.; MÓNICO, L. S. M.; PINTO, V. A.; PINTO, C. A.; ALEGRE, M. I.; OLIVEIRA, D.; PARREIRA, P. M. Interferência Trabalho-Família e facilitação Trabalho-Família: estudo da invariância da medida entre sexos. Revista Psicologia: Teoria e Prática, n. 20, v. 2, p. 20-41. São Paulo, maio/ago. 2018. http://dx.doi.org/10.5935/1980-6906/psicologia.v20n2p42-63

CARVALHO, C.; ANDRADE, M. A síndrome de Burnout em docentes do ensino superior: o papel do conflito trabalho-família. In C. Carvalho, P. Lourenço, \& C. Peralta (Orgs.), A emoção nas organizações, p. 111-136, Viseu: PsicoSoma, 2012.

COLAIZZI, P. F. Psychological research as the phenomenologist views it. in R. S. Valle \& M. King (Eds.), Existential phenomenological alternatives for psychology (pp. 48-69). New York: Oxford University Press. 1978.

DOHERTY, Liz; MANFREDI, Simonetta. Action research to develop work-life balance in a UK university, Women in Management Review, v. 21, n. 3 p. 241-259, 2006. http://dx.doi.org/10.1108/09649420610657416 
EDWARDS, J. R.; ROTHBARD, N. P. Mechanismslinking work and family:Clarifying the relationship between work and family constructs. Academy of Management Review, 25(1), p. 178-199, 2000. https://doi.org/10.5465/amr.2000.2791609

FEIJÓ, M. R.; GOULART JUNIOR, E.; NASCIMENTO, M. J.; NASCIMENTO, N. B. Conflito Trabalhofamília: Um Estudo sobre a Temática no Âmbito Brasileiro. Pensando Famílias, v.21, n.1, p. 105-119, jul. 2017. Disponível em: http://pepsic.bvsalud.org/scielo.php?script=sci serial\&pid=1679-494X\&lng=pt\&nrm=iso

Acesso em: 12 jun. 2020.

FOTHERGILL, Alice; FELTEY, Kathryn. I've worked hard and splept and little. Mothers on the tenure rack in academia. Journal of the association for research on mothering, v.5, v.2, p. 719, 2004. Disponível em: file:///C:/Users/slpsc/Music/FWA/aCADEMICA/30\%20Feltel.pdf Acesso em; $12 / 06 / 2020$.

FOX, M. F.; FONSECA, C.; BAO, J. Work and family conflict in academic science: Patterns and predictors among women and men in research universities. Social Studies of Science, n. 41, v.5, p. 715-735, 2011. https://doi:10.1177/030631271141773

FOX, Mary Frank. Gender, Family Characteristics, and Publication Productivity among Scientists. Social Studies of Science. n. 35, v.1, p. 131-150, fev, 2005.

https://doi:10.1177/0306312705046630

GIL, A. Como elaborar projetos de pesquisa. 5. ed. São Paulo: Atlas, 2010.

GREENHAUS, J. H.; BEUTELL, N. J. Sources of conflict between work and family roles. Academy of Management Review, v. 10, n. 1, p. 76-88, 1985. Disponível em: http://www.jstor.com/stable/258214 acesso em: 14 mai. 2020.

HARDY, A.; MCDONALD, J.; GUIJT, R.; LEANE, E.; MARTIN, A.; JAMES, A.; JONES, M.; CORBAN, M.; GREEN, B. Academic parenting: work-family conflict and strategies across child age, disciplines and career level, Studies in Higher Education, v. 43, n.4, p. 625-643, 2016. https://doi.org/10.1080/03075079.2016.1185777

HASLAM, D. M.; SANDERS, M. R.; SOFRONOFF, K. Reducing Work and Family Conflict in Teachers: A Randomised Controlled Trial of Workplace Triple P. School Mental Health, n. 5, p.70-82, 2013. https://doi:0.1007/s12310-012-9091-z

HIRAKATA, P. E.; DANILUK, J. C. Swimming Upstream: The Experience of Academic Mothers of Young Children. anadian Journal of Counselling/Revue canadienne de counseling, v. 43, n.4, p. 283-294, 2009. Disponível em: file:///C:/Users/slpsc/Music/FWA/aCADEMICA/33\%20Hirakata.pdf Acesso em: 16/06/2020.

HOWE-WALSH, L.; TURNBULL, S. Barriers to Women Leaders in Academia: Tales from Science and Technology. Studies in Higher Education. 2014. http://doi:10.1080/03075079.2014.929102.

LAROCCA, P.; ROSSO, A.; SOUZA, A. A formulação dos objetivos de pesquisa na pós-graduação em Educação: uma discussão necessária. RBPG, v. 2, n. 3, p. 118-133, mar, 2005. https://doi.org/10.21713/2358-2332.2005.v2.62

Perspectivas em Gestão \& Conhecimento, João Pessoa, v. 11, n.1, p. 118-143, jan./abr. 2021. 
MARCONI, Marina de Andrade; LAKATOS, Eva Maria. Fundamentos de metodologia científica. 6. ed. São Paulo: Atlas, 2009.

MISHLER, E. G. Research interviewing: Context and narrative. Cambridge, MA: Harvard University Press, 1986.

MOREIRA, M. G.; SILVA HENNING, A. A influência do conflito trabalho-família e o comprometimento com a carreira na percepção de sucesso na carreira de mulheres docentes. Revista Alcance Eletrônica, Caribe, Espanha e Portugal. v. 25, n. 2, mai./ago. 2018. http://doi:alcance.v25n2

NOOR, KHAIRUNNEEZAM. Work-Life Balance and Intention to Leave among Academics in Malaysian Public Higher Education Institutions. International Journal of Business and Social Science. Malaysia. v. 2 n. 11 Edição Especial, 2011. http://doi:10.30845/ijbss

O'MEARA, K.; CAMPBELL, C. Faculty Sense of Agency in Decisions About Work and Family. The Review of Higher Education, n. 34, v.3, p. 447-76, 2011. https://doi:org/10.1353/rhe.2011.0000

POWELL, G.N.; GREENHAUS, J.H. Is the opposite of positive negative? Untangling the complex relationship between work-family enrichment and conflict, Career Development International, v. 11, n. 7, p. 650-659. 2006. https://doi.org/10.1108/13620430610713508

QUEVEDO, L. DE B.; FLECK, C. F.; CARMO, K. L. F. do. O regime de dedicação exclusiva e a gestão do tempo: estudo de caso com docentes universitários. RECAPE - Revista de Carreira e Pessoas, p. 20-33, 2013. https://doi.org/10.20503/recape.v3i3.17673

RAFNSDÓTTIR, G. L.; HEIJSTRA, T. M. Balancing Work Family Life in Academia: The Power of Time. Gender, Work and Organization. 2011. https://doi:10.1111/j.1468-0432.2011.00571.x

REDDICK, R. J.; ROCHLEN, A. B.; GRASSO, J. R.; REILLY, E. D.; SPIKES, D. D. Academic Fathers Pursuing Tenure: A Qualitative Study of Work-Family Conflict, Coping Strategies, and Departmental Culture. Psychology of Men \& Masculinity, v. 13, n. 1, p. 1-15, 2012. https://doi:10.1037/a0023206

SANTOS, G. G.; CARDOSO, C. C. Work-family culture in academia: a gendered view of workfamily conflict and coping strategies. NEGE Management Research Unit, University of Minho, Braga, Portugal, p. 442-457, janeiro, 2016. https://doi.org/10.1108/02683940810861356

TAKAHASHI, A. R. W.; LOURENÇO, M. L.; SANDERAND, J. A.; SOUZA, C. P. da S. Competence development and work-family conflict Professors and gender. Genderin Management: An International Journal, v. 29, n. 4, p. 210-228. 2014. http://dx.doi.org/10.1108/GM-12-2012$\underline{0100}$

TAKAHASHI, A. R. W.; LOURENÇO, M. L.; SANDERAND, J. A.; SOUZA, C. P. E agora, José?": intraempreendedorismo, desenvolvimento de competências empreendedoras e conflito trabalho-família em professores de programas de mestrado e doutorado em administração.

Perspectivas em Gestão \& Conhecimento, João Pessoa, v. 11, n.1, p. 118-143, jan./abr. 2021. 
Book of Proceedings: Tourism and Management Studies International, Conference Algarve Portugal, v. 4, p.1208 - 1219, 2012.

THEÓPHILO, C. R.; IUDÍCIBUS, S. Uma análise crítico-epistemológica da produção científica em contabilidade no Brasil. UnB Contábil, v. 8, n. 2, p. 145-175, 2005.

VILELA, Nágila Giovanna Silva. Conflito Trabalho-Família: uma Revisão Sistemática da Produção Científica Nacional. Revista Liceu On-line, São Paulo, v. 8, n. 1, p. 27-49, jan./jun. 2018. Disponível em: https://liceu.fecap.br/LICEU ON-LINE/article/view/1434/877 acesso em: 16 abr. 2020.

VILELA, N. G. S.; LOURENÇO, M. L.; KAI, F. O.; ÁVILA, L. K. M. Panorama da produção acadêmica internacional sobre conflito trabalho-família. Revista Adm. FACES Journal, Belo Horizonte v. 17 n. 3 p. 64-83 jul./set. 2018. https://doi.org/10.21714/1984-6975FACES2018V17N3ART5665

VILELA, Nágila Giovanna Silva. LOURENÇO, Mariane Lemos. Conflito trabalho-família, políticas de apoio à família e gênero: um panorama do atual cenário de estudos. Revista Eletrônica de

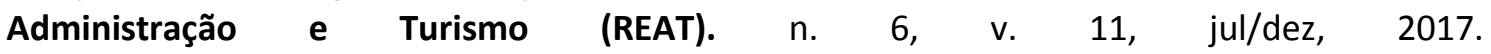
http://dx.doi.org/10.15210/reat.v11i6.12498

WENDEL, L. E. W.; WARD, K. Academic life and motherhood: variations by institutional type. Higher Education, n. 52, p.487-521, 2006. https://Doi:10.1007/s10734-005-0364-4

WILLIAMS, J. C. HITTING. the maternal wall. Academe, n. 90, v.6, p.16-20. 2004. Disponível em: $\quad$ https://pdfs.semanticscholar.org/d783/3a0f2ed908d5ef890169067523398f7efe52.pdf acesso em 11 jul. 2020.

WOLFINGER, N.; M. MASON.; GOLDEN, M. Problems in the Pipeline: Gender, Marriage, and Fertility in the Ivory Tower. The Journal of Higher Education. n.79, v. 4, P. 388-405. 2008. Disponível em: https://www.jstor.org/stable/25144681?seq=1\&cid=pdf-reference acesso em: 14 jul. 2020.

Recebido em/Received: 26/08/2020 | Aprovado em/Approved: 29/12/2020 